\title{
Vector Competence of Eucampsipoda africana (Diptera: Nycteribiidae) for Marburg Virus Transmission in Rousettus aegyptiacus (Chiroptera: Pteropodidae)
}

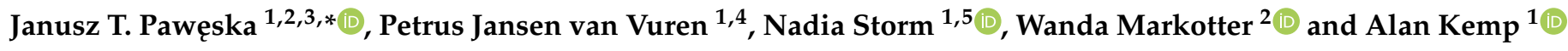 \\ 1 Centre for Emerging Zoonotic and Parasitic Diseases, National Institute for Communicable Diseases of the \\ National Health Laboratory Service, Sandringham 2131, South Africa; \\ Petrus.Jansenvanvuren@csiro.au (P.J.v.V.); nstorm@bu.edu (N.S.); alank@nicd.ac.za (A.K.) \\ 2 Centre for Viral Zoonoses, Department of Medical Virology, Faculty of Health Sciences, University of Pretoria, \\ Pretoria 0001, South Africa; Wanda.Markotter@up.ac.za \\ 3 School of Pathology, Faculty of Health Sciences, University of Witwatersrand, \\ Johannesburg 2050, South Africa \\ 4 Australian Centre for Disease Preparedness, CSIRO Health \& Biosecurity, Geelong, VIC 3220, Australia \\ 5 Department of Microbiology, School of Medicine, Boston University, Boston, MA 02118, USA \\ * Correspondence: januszp@nicd.ac.za; Tel.: +27-(11)-3866336
}

\section{check for} updates

Citation: Pawęska, J.T.; Jansen van Vuren, P.; Storm, N.; Markotter, W.; Kemp, A. Vector Competence of Eucampsipoda africana (Diptera:

Nycteribiidae) for Marburg Virus Transmission in Rousettus aegyptiacus (Chiroptera: Pteropodidae). Viruses 2021, 13, 2226. https://doi.org/ $10.3390 / \mathrm{v} 13112226$

Academic Editors: Giulietta Venturi, Claudia Fortuna and Marco Di Luca

Received: 15 September 2021

Accepted: 28 October 2021

Published: 4 November 2021

Publisher's Note: MDPI stays neutral with regard to jurisdictional claims in published maps and institutional affiliations.

Copyright: (c) 2021 by the authors. Licensee MDPI, Basel, Switzerland. This article is an open access article distributed under the terms and conditions of the Creative Commons Attribution (CC BY) license (https:// creativecommons.org/licenses/by/ $4.0 /)$.

\begin{abstract}
This study aimed to determine the vector competence of bat-associated nycteribiid flies (Eucamsipoda africana) for Marburg virus (MARV) in the Egyptian Rousette Bat (ERB), Rousettus aegyptiacus. In flies fed on subcutaneously infected ERBs and tested from 3 to 43 days post infection (dpi), MARV was detected only in those that took blood during the peak of viremia, 5-7 dpi. Seroconversion did not occur in control bats in contact with MARV-infected bats infested with bat flies up to 43 days post exposure. In flies inoculated intra-coelomically with MARV and tested on days $0-29$ post inoculation, only those assayed on day 0 and day 7 after inoculation were positive by q-RT-PCR, but the virus concentration was consistent with that of the inoculum. Bats remained MARV-seronegative up to 38 days after infestation and exposure to inoculated flies. The first filial generation pupae and flies collected at different times during the experiments were all negative by q-RT-PCR. Of 1693 nycteribiid flies collected from a wild ERB colony in Mahune Cave, South Africa where the enzootic transmission of MARV occurs, only one $(0.06 \%)$ tested positive for the presence of MARV RNA. Our findings seem to demonstrate that bat flies do not play a significant role in the transmission and enzootic maintenance of MARV. However, ERBs eat nycteribiid flies; thus, the mechanical transmission of the virus through the exposure of damaged mucous membranes and/or skin to flies engorged with contaminated blood cannot be ruled out.
\end{abstract}

Keywords: Marburg virus; bat flies; vector competence; field infection rate; transmission; Egyptian rousette bat

\section{Introduction}

Marburg virus (MARV), species Marburg marburgvirus (Filoviridae) [1], causes sporadic but often fatal Marburg Virus Disease (MVD) in humans [2]. To date, fourteen outbreaks of MVD have been reported, most occurring in sub-Saharan Africa [2,3], but a single MVD case was reported in August 2021 from Guinea, West Africa [4]. Evidence of marburgvirus circulation was also reported from countries where MVD cases have not been recorded [5-7]. The first recognised outbreak of MVD in Africa occurred in 1975 [8] with the largest and most deadly reported from Angola in 2004-2005, with a case-fatality rate of $90 \%$ [9].

In the past two decades, there has been significant progress in studies of bats as reservoirs of diverse pathogens of public health importance [10,11], including filoviruses [12-14], coronaviruses [15-20], paramyxoviruses [19,21-24], and lyssaviruses [25,26]. The results of 
ecological, epidemiological, and experimental studies implicate the ERB as the prime reservoir host for marburgviruses [13,14,27-33].The roosting habitats of the Egyptian Rousette Bat (ERB), Rousettus aegyptiacus, including caves and mines, have been associated with infection of humans with MARV [13,14,27,34-38].

The identification of natural entry and exit portals for marburgviruses in ERBs and, consequently, mechanisms involved in the maintenance of marburgviruses in bat colonies remain elusive. Experimental studies demonstrated that the infection of ERBs with MARV results in viremia and replication of the virus in multiple tissues, including organs compatible with viral shedding (salivary gland, kidney, bladder, intestines, reproductive tract) [28-33]. It appears that the clearance of MARV from the salivary glands of experimentally infected ERBs is slower than from other tissues [30-32].

Both oral and faecal shedding of MARV has been demonstrated in wild caught and experimentally infected captive-bred ERBs [14,30-32,39]. Oral shedding resulting in contamination of the oral cavity might contribute to MARV transmission via biting. Biting is observed among ERBs, with juveniles being the most adversely affected, as they are bitten by older bats displaying dominance. Potential faecal-oral transmission of marburgviruses highlights the risk of environmental contamination, and ERB roosting sites might be a source of virus spillover to humans. Roosting behaviour, including clustering into close and dense groups, auto-, and allo-grooming result in direct physical contact that would support faecal-oral transmission of marburgviruses in bats. Moreover, biting by hematophagous ectoparasites might result in inoculation of wounds with contaminated saliva and faeces or exposure to contaminated fomites. However, it remains unknown if faecal-oral transmission represents a natural portal of entry for marburgviruses, to what extent viral shedding patterns found in captive-bred ERBs can be extrapolated to natural settings, and whether this mode of transmission represents a sustainable mechanism for the enzootic perpetuation of marburgviruses.

Limited experimental studies of horizontal transmission of MARV between experimentally infected and naïve in-contact ERBs have yielded intriguing results [29,32]. In a study by Paweska et al. [29], neither seroconversion nor viremia could be demonstrated in any of 14 in-contact susceptible ERBs up to 42 days after exposure to 22 infected bats by subcutaneous (SC) MARV inoculation, despite demonstrable shedding of the virus via saliva, faeces, and urine. A similar MARV transmission experiment was conducted by Schuh et al. [32] for a period of 9 months. In this study, SC-infected donor bats were cohoused for 56 days directly with naïve contact bats or placed over cages of additional naïve bats, thus potentially exposing them to infectious urine, faeces, and fruit spats. Thereafter, all bats were grouped and housed together for an additional 7 months. MARV shedding in saliva or urine was detected in 11 of 12 inoculated bats between 5 and 19 days post infection (PI). Interestingly, MARV viremia was only detected in three naïve contact bats at 7 months PI, one of which tested positive by oral swab. Two of these three bats seroconverted by 8 months PI, and by 9 months PI, nine (37.5\%) of the 24 naïve contacts bats had seroconverted. While it is rather puzzling why less than half of the naïve contact bats seroconverted, this study suggests a prolonged incubation period (up to 7-8 months) in in-contact infected bats after extended exposure to MARV-infected donor bats and their bodily secretions. The mechanism by which the virus could survive in in-contact infected bats during this lengthy incubation remains unclear. The establishment of persistent infection in immune-privileged sites, at least in some proportion of MARV-infected ERBs, might be one possibility.

MARV has been shown to be present in the male and female reproductive tracts of experimentally infected ERBs [29]. Both MARV and Zaire ebolavirus have been isolated from human seminal fluids months after the patient's full clinical recovery [40-43], which may serve as additional evidence for a sexual route of MARV transmission in ERBs. During the 2014-2016 West African Ebola Virus Disease (EVD) epidemic, sporadic transmission events resulted in the initiation of new chains of human-to-human transmission. Multiple reports suggest that these re-emergences were linked to persistent EBOV infections and 
included sexual transmission from EVD survivors [44-49]. Ebola virus RNA has also been detected in other immunologically privileged sites in humans and non-human primates such as the central nervous system and eyes [50-54].

The role of ectoparasites in filovirus transmission has been postulated [55]. While it appears that MARV can be horizontally transmitted among ERBs under experimental conditions in the absence of arthropods [32], the potential for arthropod involvement as an intermediate host has never been definitively disproven.

Hematophagous arthropods are responsible for the biological or mechanical transmission of numerous human and animal pathogens such as viruses, bacteria, protozoa, and helminths that can be acquired through ingestion or by contact [56-58]. Bats are parasitised by a number of ectoparasites, including mites, bat flies, ticks, and fleas [59]. One of aspects of the host-pathogens relationship is the role of ectoparasites as reservoirs and vectors of zoonotic diseases, including hematophagous bat flies of families Streblidae and Nycteribiidae. Members of these two families are highly host-specific obligate ectoparasites of bats [59-62] and are potentially capable of mechanical or biological pathogen transmission. Bartonella and Rickettsia [63-65], viruses from the Rhabdoviridae family [66,67], and protozoans including the hematoparasite Polychromophilus [68] have been detected in bat flies.

Kunz and Hofmann [69] successfully propagated MARV in experimentally inoculated Aedes aegypti (Diptera: Culicidae), but not in Anopheles maculipennis and castor bean ticks (Ixodes ricinus). Different arthropods species have been tested as part of ecological investigations in past filovirus outbreaks, without any positive results, but these studies excluded bat flies [42,70-72]. Bat flies (Diptera: Nycteribiidae) and argasid ticks, Ornithodoros faini, collected directly from bats and off the walls at the roost sites in Python Cave where active marburgvirus infection was occurring, tested negative for marburgviruses $[14,38]$, but their number tested was too low to reasonably determine that these ectoparasites are not involved in the marburgvirus transmission. Schuh et al. [73] presented more evidence after testing 3125 O. faini ticks collected from the walls of Python Cave, where ERBs were roosting. All were negative for marburgviruses, indicating that these ticks do not act as replication or mechanical vectors for marburgviruses in ERB populations.

Results of recent studies in South Africa demonstrate enzootic and very efficient marburgvirus circulation in ERBs roosting at Matlapitsi Cave, which is located in the rural area of the Limpopo province of the country $[39,74]$. This colony is heavily infested by hematophagous ectoparasites throughout the year and particularly by nycteribiid flies Eucampsipoda africana (Diptera: Nycteribiidae). A novel fusogenic orthoreovirus and a novel orthobunyavirus have been isolated from E. africana collected from ERBs in this cave $[75,76]$.

Knowledge on natural filovirus transmission would help to understand the mechanisms involved in zoonotic spillover and aid public health control measures. The development of viremia observed in ERBs after experimental subcutaneous infection with MARV [28-33] suggests that blood-sucking ectoparasites might be involved in the maintenance and perpetuation of the virus. Our study aimed to determine the vector competence of E. africana for the replication and transmission of MARV to ERBs. In addition, we tested nycteribiid flies collected from ERBs in Matlapitsi Cave to determine the field infection rate for marburgvirus.

\section{Materials and Methods}

\subsection{Description and Ecology of Matlapitsi Cave}

The Matlapitsi cave (previously also called Mahune cave) $[39,77]$ is located in the indigenous flora of the Matlapitsi Valley $\left(24^{\circ} 1^{\prime} \mathrm{S}, 30^{\circ} 10^{\prime} \mathrm{E}\right)$ on the north-eastern slope of the Wolkberg Mountain range, bordering the Lekgalameetse Nature Reserve in the Limpopo province, South Africa. The cave is situated in close proximity to the semi-rural community of Fertilis, which is hidden by the indigenous flora (Figure 1A). It is inhabited by a large ERB population, which represents a maternity colony. In the Matlapitsi Valley, figs form 
the basis for this cave-dweller bats' diet, in particular Ficus sycamorus (Figure 1B), but $F$. petersii and F. sansibarica and other fruits are also eaten at certain times of the year [77].

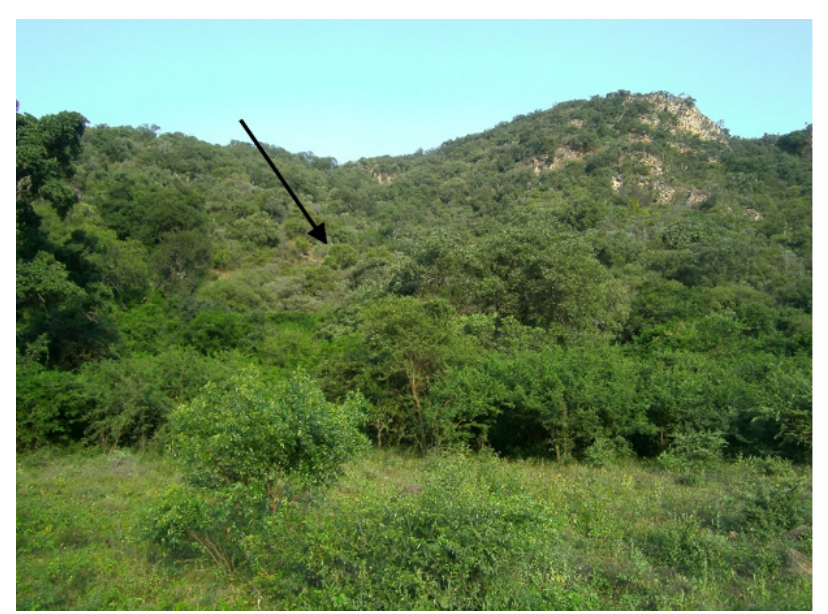

(A)

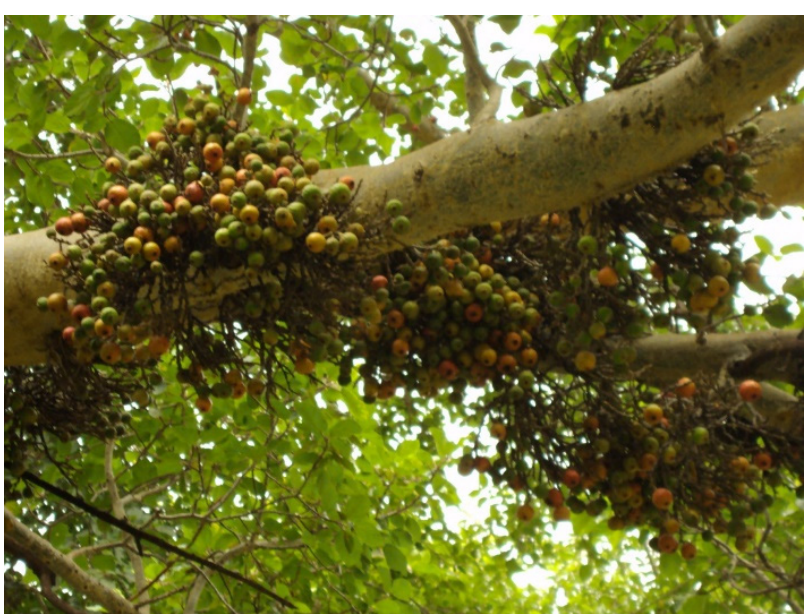

(B)

Figure 1. Location of entry to Matlapitsi cave (indicated by arrow) inhabiting R. aegyptiacus colony, Matlapitsi Valley, Limpopo province, South Africa (A); Cape fig tree with fruits, which is a preferred food for R. aegyptiacus (B).

The approximately $5 \mathrm{~m}$ arched opening of the cave leads into the main chamber of about $6000 \mathrm{~m}^{3}$. The cave floor slopes away steeply from the entry, leaving the roof some $7 \mathrm{~m}$ above, whilst the cave widens to almost $34 \mathrm{~m}$ and extends $28 \mathrm{~m}$ horizontally into the mountain. Proceeding $20 \mathrm{~m}$ south-west into the cave, an aggregation of $2-3 \mathrm{~m}^{3}$ boulders towers towards the ceiling, where the ERBs roost across the creviced roof. The back corner of the cave drops $9.5 \mathrm{~m}$ to a smaller second chamber of about $700 \mathrm{~m}^{3}, 15 \mathrm{~m}$ at its widest, $4.5 \mathrm{~m}$ at its highest, and extending another $12 \mathrm{~m}$ south by southwest into the rock. This second chamber appears to reach the water table, with a yearlong clear still pool and is frequented by the Natal long-fingered bat (Miniopterus natalensis). Branching off northwest from the second chamber is a $6 \mathrm{~m}^{3}$ alcove, which hosts two small crawl spaces that lead to the third chamber. This last chamber is about $9 \mathrm{~m}$ long with the roof only 3.8 overhead and extends west by southwest before extending into a tunnel almost $2 \mathrm{~m}$ in diameter that extends for another $12.7 \mathrm{~m}$ before terminating abruptly in a solid rock fall (Figure 2).

The Matlapitsi ERB population represents a nursery colony with fluctuating numbers during the year. The population density increases during the hot, rainy season (OctoberFebruary) when food is the most abundant, reaches a maximum during March-April, and declines in numbers from June to July when food availability is low [77]. Apart from ERB and $M$. natalensis, the following bat species are present at Matlapitsi cave: short-eared Trident bat (Cloeotis percivali), Temminck's hairy bat (Myotis tricolor), Hildebrandt's horseshoe bat (Rhinolophus hildebrandtii), the Bushveld horseshoe bat (Rhinolophus Simulator), Blasius's horseshoe bat (Rhinolophus blasii), Darling's horseshoe bat (Rhinolophus darlingi), Geoffroy's horseshoe bat (Rhinolophus clivosus), Sundevall's roundleaf bat/Sundevall's leaf-nosed bat (Hipposideros caffer), and the Egyptian slit-faced bat (Nycteris thebaica). The ERBs permanently and almost exclusively inhabit the main chamber of the cave. The second and third chamber is frequented by M. natalensis throughout the year, but their numbers are particularly high (several thousand) from October until December. M. natalensis is accompanied by smaller numbers of $M$. tricolor and $H$. caffer. The other year-long inhabitants, $N$. thebaica and Rhinolophus spp., have been observed roosting in both the alcove and in the small crawl spaces of the cave entrance. Other animal species observed around the cave include Cape porcupine (Hystrix africaeaustralis), vervet monkey (Chlorocebus pygerythrus), the common genet (Genetta genetta), baboons (Papioursinus), black-backed jackals (Canis mesomelas), and domesticated goats (Capra aegagrus hircus). Black mamba (Dendroaspis polylepis) has been 
seen near the cave entrance, whilst a pair of resident African rock pythons (Python sebae) have been observed catching and eating bats.

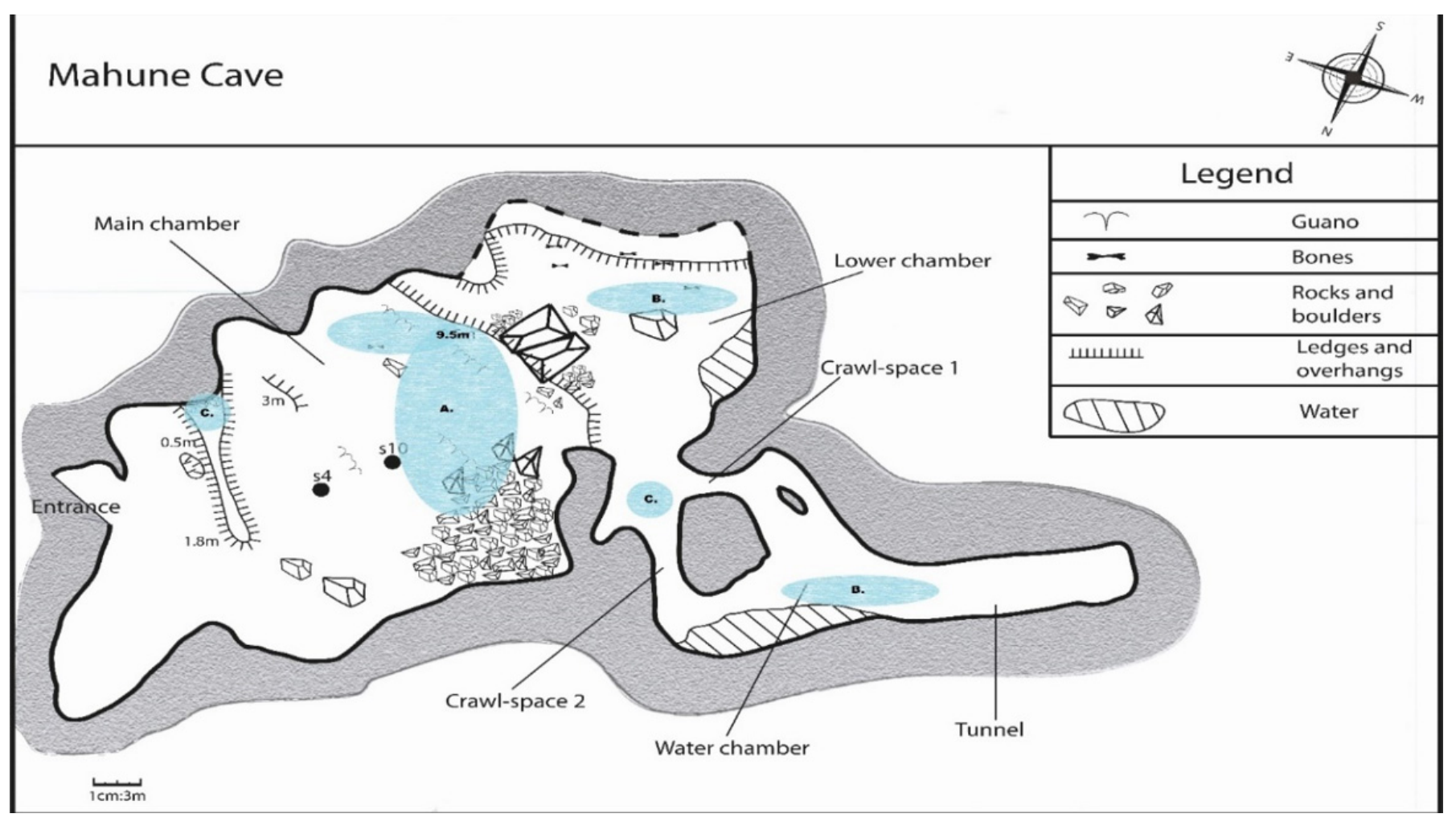

Figure 2. Transectional view of Matlapitsi cave system at a scale of $1 \mathrm{~cm}: 3 \mathrm{~m}$ : Shaded area A. indicates the roosting area of Rousettus aegyptiacus in the main chamber of the cave. Shaded areas B. indicate the areas where Miniopterus natalensis, Myotis tricolor, and Hipposideros caffer roost when present. Shaded areas C. indicate the only areas that Nycteris thebaica and Rhinolophus spp. have been observed roosting.

During monthly visits to the cave from June 2012 to July 2018, infestation of bats by different ectoparasites, including mites, ticks, fleas, and bat flies of families Streblidae and Nycteribiidae was noted throughout the year. Bat flies E. africana (family Nycterbiidae) have been found predominantly on ERB and $N$. thebaica bats. The identification and confirmation of bat fly species infesting ERBs bats was done using a morphological key [78] and by the amplification of the cytochrome c oxidase subunit I (COI) gene using barcoding primers as previously described [75].

The annual average temperature recorded at the roost of the cave from 2014 to 2018 was $21.8^{\circ} \mathrm{C}$ with a minimum of $18.5^{\circ} \mathrm{C}$ and maximum of $34.6{ }^{\circ} \mathrm{C}$, and the annual average relative humidity ( $\mathrm{RH}$ ) was $86.8 \%$ with minimum of $48.4 \%$ and maximum of $98.6 \%$. Temperature and RH were recorded using data loggers LogTag ${ }^{\circledR}$ HAXO-8 Humidity \& Temperature Recorder (LogTag ${ }^{\circledR}$ Recorders, Cape Town, South Africa).

\subsection{Collection of Bat Flies from Egyptian Rousette Bats}

ERBs were captured at Matlapitsi Cave, using two harp traps (G5 Bat Trap, Bat Conservation and Management, Carlisle, PA, USA) (Figure 2A) [79] across the cave entrance, with staff wearing personal protective equipment including powered air-purifying respirators and coveralls (Figure 3A) typically worn in biosafety level 3 (BSL3) laboratory environments [14]. All staff involved in bat trapping and sampling had been vaccinated against rabies previously. The collection bag of each harp trap was checked every 10-20 min; trapped bats were removed and temporally placed in individual cotton bags prior to sampling (Figure 2B). 


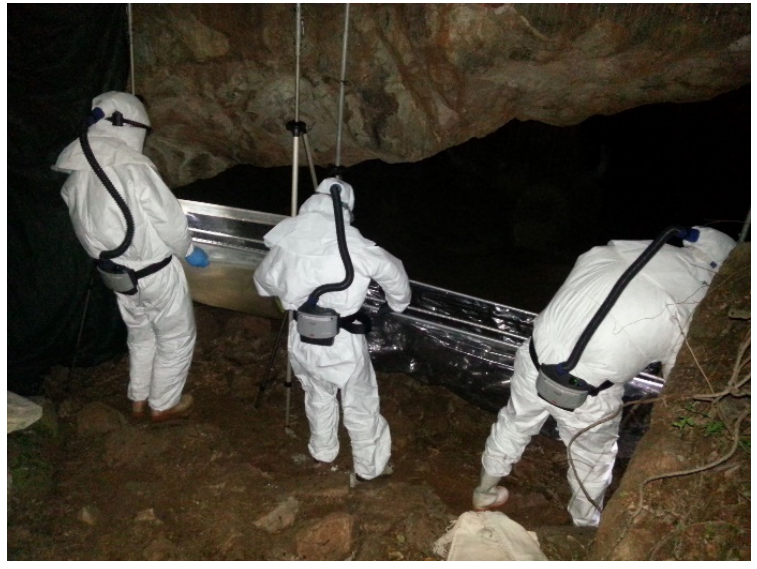

(A)

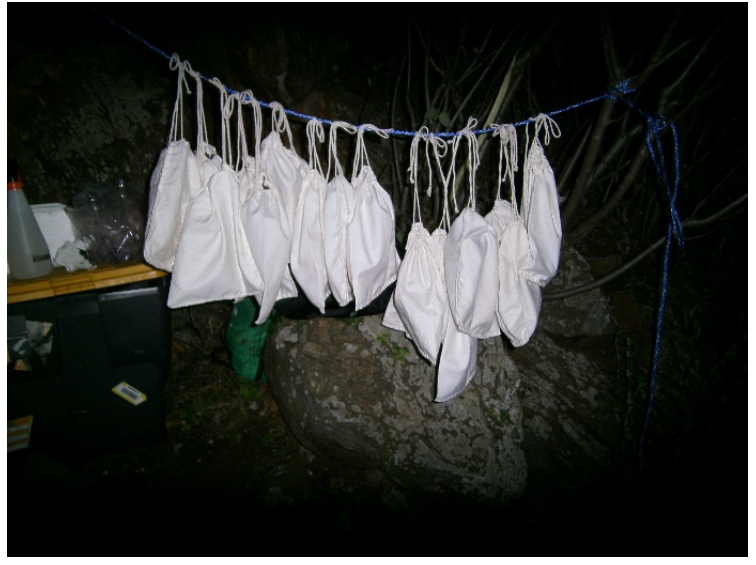

(B)

Figure 3. Collecting of bats trapped in harp traps by operators dressed in BSL3 personal protective equipment at the entrance to Matlapitsi cave, Matlapitsi Valley, Limpopo province, South Africa (A); Captured R. aegyptiacus placed in individual cotton bags until sampling (B).

For laboratory testing, bat flies were collected from ERBs (Figure 4A) into $2 \mathrm{~mL}$ cryotubes (Figure 4B) containing $0.3 \mathrm{~mL}$ of Dulbecco's modified Eagle's medium (DMEM, Lonza, Basel, Switzerland). Samples were snap frozen using a vapour phase liquid nitrogen field storage container and transported to the biosafety level four laboratory (BSL4) at the National Institute for Communicable Diseases (NICD) of the National Health Laboratory Service (NICD-NHLS) in Johannesburg for further processing and testing. Collection of bat flies for laboratory testing was done from bats trapped regularly from June 2012 to July 2018 as a part of a biosurveillance project on zoonotic pathogens harboured by South African bats. The trapping and sampling of bats was usually done over two consecutive nights, from 19:00 to 24:00.

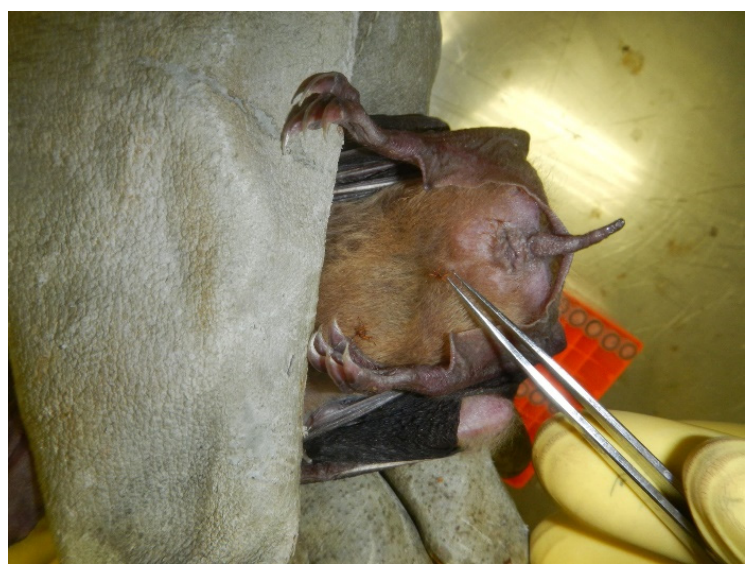

(A)

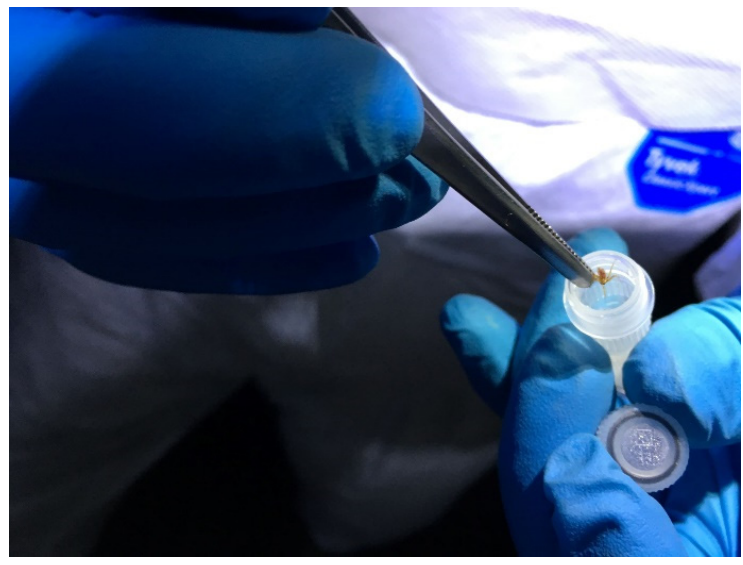

(B)

Figure 4. Field collection of bat fly Eucampsipoda africana (family Nycterbiidae) from R. aegyptiacus bats (A) into a microtube for transportation to containment facility $(\mathbf{B})$.

Our pilot experiment has demonstrated that to ensure the maximum survival of bat flies, the time from collection at Mahune cave to the time of their release on captive-bred bats in BSL4, should not be longer than 10-12 h. Therefore, to shorten the time needed for collection of the required number of flies for experimental study, they were collected at the peak of ERBs emergence from the cave, usually from 19:30 to 21:00. Flies were placed into $2 \mathrm{~mL}$ cryotubes containing a small piece of wetted paper towel and transported in microtube storage boxes as soon as feasible from the Matlapitsi cave site to NICD-NHLS BSL4 (about $5 \mathrm{~h}$ drive) for further handling. 


\subsection{Infestation Rate of Egyptian Rousette Bats by Bat Flies}

The bat fly infestation rate of ERBs roosting at Matlapitsi cave was calculated based on two collections made in November 2016 using trapping and sampling procedures as described in Section 2.2.

\subsection{Marburg Virus Infection Rate in Bat Flies}

A total of 1653 bat flies collected from ERBs roosting at Matlapitsi cave between June 2012 and July 2018 were processed for laboratory testing. Bat flies were transferred into $2 \mathrm{~mL}$ grinding tubes and homogenised at $30 \mathrm{~Hz}$ for eight minutes using a Tissuelyzer II (Qiagen, Hilden, Germany) and $5 \mathrm{~mm}$ stainless steel beads (Qiagen). Cellular debris was removed by centrifugation at $14,000 \times g$ for $3 \mathrm{~min}$, and the supernatant was used for virus isolation and detection of MARV RNA as previously described [28,75].

\subsection{Experimental Animals}

The source for ERBs bats and trapping procedures were the same as described previously for the experimental infection study with MARV [29]. Wild caught bats were transported to a BSL3 animal quarantine facility where they were kept for 6 weeks in custom-designed stainless steel cages. Bats were housed in groups of 5-6 animals per cage (Figure 5A), which were placed in negative pressure HEPA-filtered cabinets (Techniplast, West Chester, PA, USA) and fed as previously described [28,29]. Bats were tested at 3-weekly intervals to confirm that they remained serologically negative for antibodies against filoviruses or rabies-related lyssaviruses prior to moving to a flight cage for housing (Figure 5B). Colony conditions were maintained as previously described [28,29].

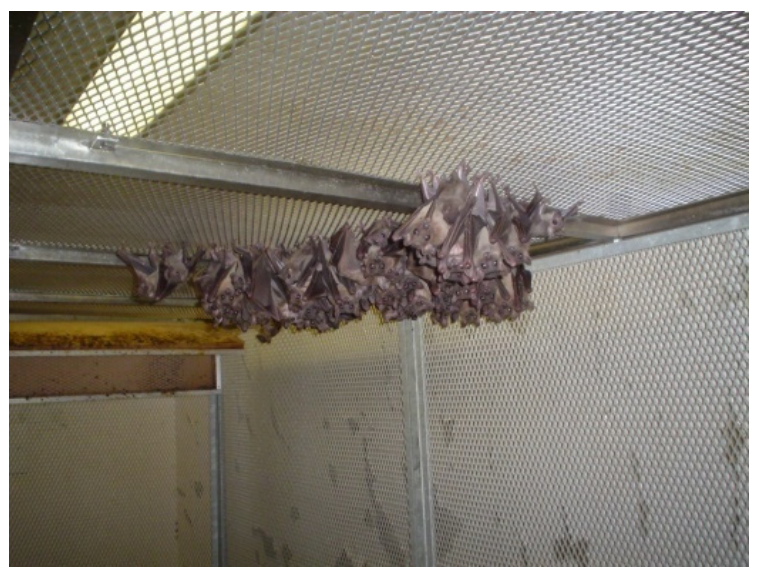

(A)

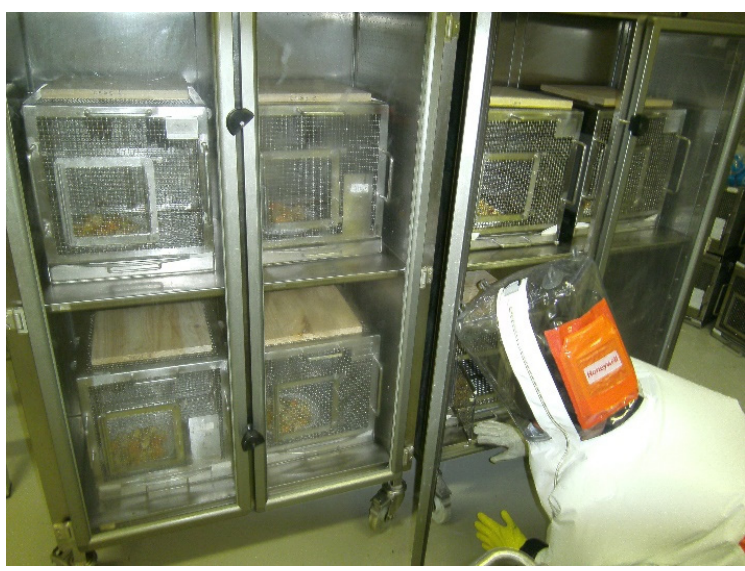

(B)

Figure 5. R. aegyptiacus colony in flight cage (A). Negative pressure HEPA-filtered animal isolators (Techniplast, West Chester, PA, USA) with custom designed stainless steel cages for housing bats in BSL4, NICD-NHLS, Johannesburg, South Africa; untreated wooden planks placed on the celling of cages serving as a roosting substrate for laying bat fly pupae (B).

All work with infectious virus, inoculated animals, and bat flies was conducted at the Centre for Emerging and Zoonotic Diseases, NICD-NHLS, Sandringham, South Africa in a BSL4 laboratory. Bats were transported from the flight cage (Figure 5A) to BSL4 and housed in the same cages, and animal isolators were as used in BSL3 during a quarantine period, except for having an untreated wooden plank (pine wood) placed on the celling of the cage, which served as a roosting substrate for depositing pupas by bat flies (Figure 5B). Bats were acclimatised to the BSL4 environment for one week before the experimental procedures started, were fed fresh tropical fruits and provided with fresh water ad libitum, and were monitored daily for the development of clinical signs as well as for food intake.

Husbandry procedures and environmental conditions were identical to those previously described [28] with some modifications. To enhance the RH, animal isolators were modified to allow for an intake of mist produced by humidifiers (Electra, Johannesburg, 
South Africa). A single humidifier enclosed in a custom-made housing was placed on the celling of the Techniplast cabinet in such a way that the discharged steam could be directed by cabinet vertical airflow into the interior of the isolator (technical modification of Techniplast cabinet for housing a humidifier is available on request). Temperature and $\mathrm{RH}$ inside animal isolators were monitored using the same data loggers as those used to take temperature and RH measurements in Matlapitsi cave.

\subsection{Virus Stock}

The SPU 148/99/1 isolate of MARV (second passage in Vero cells) isolated from the serum of a patient who contracted a fatal MVD disease in 1999 in Watsa, Democratic Republic of Congo was used for the subcutaneous (SC) inoculation of bats as described before [29] and for intra-coelomic (IC) inoculation of bat flies.

\subsection{Experimental Infections}

Experiment I: The aim of this experiment was twofold: (1) to investigate the oral susceptibility of bat flies to MARV following feeding on viremic bats, (2) to attempt the transmission of MARV by bat flies from viremic bats to in-contact MARV-seronegative control bats. A week before any experimental procedures started, $35 \mathrm{MARV}$-seronegative bats, aged 8-12 months, were moved from a flight cage in a BSL3 animal facility to a BSL4 animal containment room. After one week of acclimatisation in BSL4, 27 ERBs were inoculated SC with $100 \mu \mathrm{L}$ of tissue culture supernatant containing $10^{5.3} \mathrm{~mL} \mathrm{TCID} 50$ of MARV, and 8 ERBs were mock inoculated SC with $100 \mu \mathrm{L}$ of Eagle's minimal essential medium (EMEM).

Bats were subdivided into six cages (C1-C6). $\mathrm{C} 1-\mathrm{C} 3$ and $\mathrm{C} 6$ contained four MARVinoculated and two contact control bats each, $\mathrm{C} 4-5$ contained six and five MARV-inoculated bats, respectively. All bats in C1-C5 were artificially infested with flies collected at Matlapitsi cave as described in Section 2.3 and released on bats within 8-10 h after collection in the field. Each bat was infested with the equal numbers of female and male flies. Bats in C6 were not infested with flies and served as controls for monitoring the potential horizontal transmission of MARV from infected to ectoparasite-free, in-contact bats. The sex of the experimental animals in each cage, the inoculation status, and the number of flies released on bats is given in Figure 6.
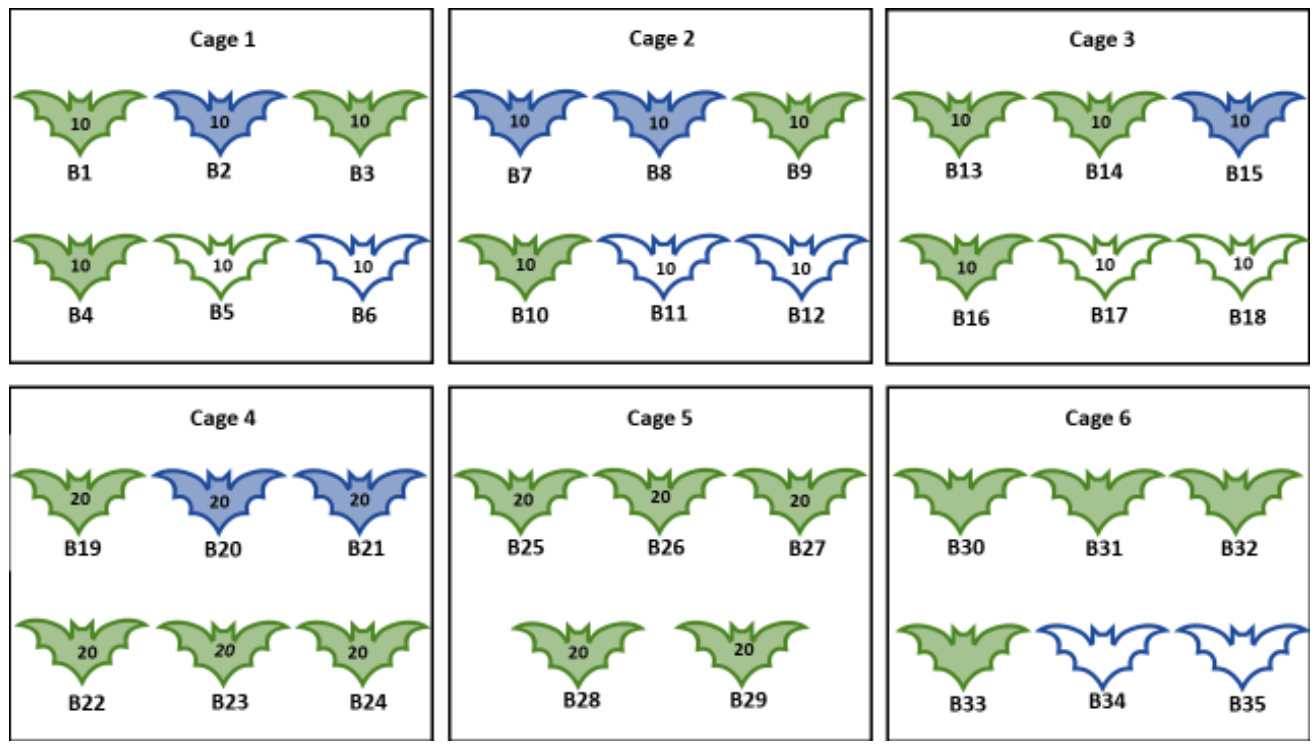

Figure 6. Experiment I. Number, sex, MARV-inoculation status of bats, and the number of bat flies released on Egyptian rousette bats. B = Bat identification number 1-35; Green outline = Female; Blue outline $=$ Male; number on the bat $=$ Number of flies released on each bat; Coloured in bats $=$ Bats inoculated with Marburg virus; Not coloured in bats = Bats mock inoculated. 
Experiment II: The aim of this experiment was twofold: (1) to investigate the susceptibility of bat flies to MARV following IC inoculation, (2) to attempt the transmission of MARV from IC-inoculated flies to MARV-seronegative bats.

As for experiment I, 18 MARV-seronegative bats aged 8-12 months were moved from the flight cage in BSL3 to the BSL4 animal containment room and placed in three cages (C7C9). After acclimatisation for one week in BSL4, all 18 bats were artificially infested with ICinoculated female flies collected at Matlapitsi Cave, as described in Section 2.3. After anaesthesia with $\mathrm{CO}_{2}$, flies were IC inoculated under a stereomicroscope with $0.34 \pm 0.02 \mu \mathrm{L}$ inoculum containing $10^{5.3} \mathrm{TCID}_{50} / \mathrm{mL}$ of MARV (68 $\pm 4 \mathrm{TCID}_{50}$ /fly). Glass needles for inoculation were made by mechanically drawing Pyrex capillary tubes to a fine point using a Leitz needle puller. Following inoculation, flies were temporarily placed in individual tubes for recovery before release onto bats. The sex and numbers of experimental ERBs in each cage, and the number of IC MARV-inoculated flies released on bats are given in Figure 7. The experimental procedures used for experiment II, including flies' anaesthesia, inoculation, and the release of inoculated flies on MARV-seronegative bats, are shown in Figure 8. In addition, the release of inoculated flies on bats in BSL4 is shown in the video supplementary material.

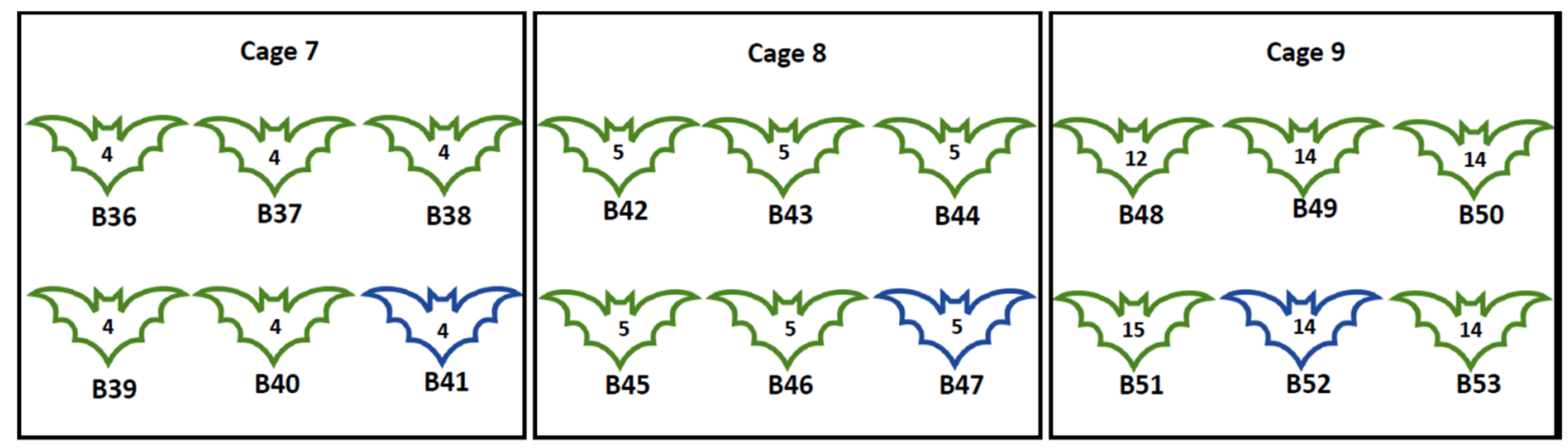

Figure 7. Experiment II. Number, sex of bats, and the number of bat MARV-inoculated flies released on seronegative Egyptian rousette bats. B = Bat identification number 36-53; Green outline = Female; Blue outline = Male; number on the bat $=$ Number of MARV-inoculated flies released on each bat.

The possibility of MARV vertical transmission by bat flies was also investigated in this study by testing F1 pupae and F1 flies collected in experiments I and II.

All animals were anaesthetised prior to inoculation and specimen collection as previously described [28]. Blood for serological and molecular testing was taken at regular intervals by either cephalic vein or cardiac puncture, and it was processed as previously described [28]. At termination of the experiments, animals were euthanised under deep anaesthesia by exsanguination via cardiac puncture [28]. All efforts were made to minimise distress. Experiment I was terminated 43 days post SC inoculation and experiment II was terminated 38 days post IC inoculation. All bats were monitored for viremia, seroconversion, food uptake, behavioural changes, and clinical symptoms. Count of adult flies, F1 pupae, and F1 flies was done visually and when flies and pupae were collected at regular intervals during experiments. Flies were collected into individual microtubes, and pupae were collected in pools (3-4 per tube) and processed as described in Section 2.5. 


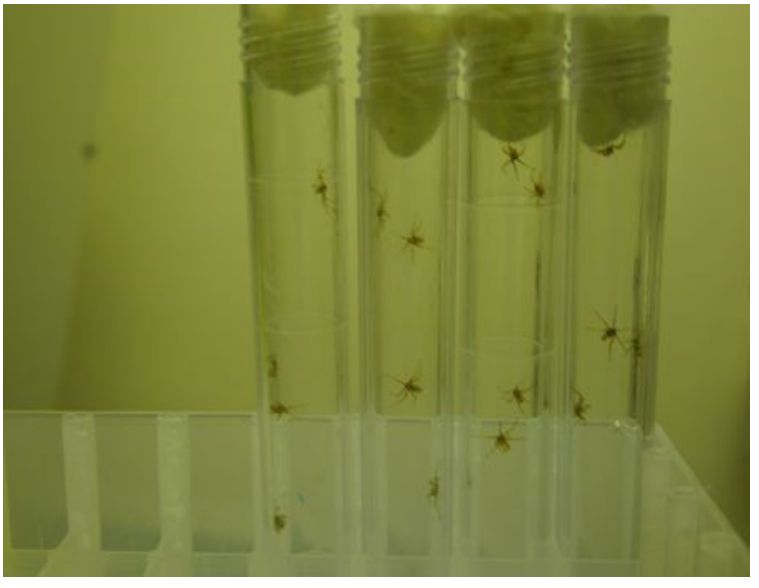

(A)

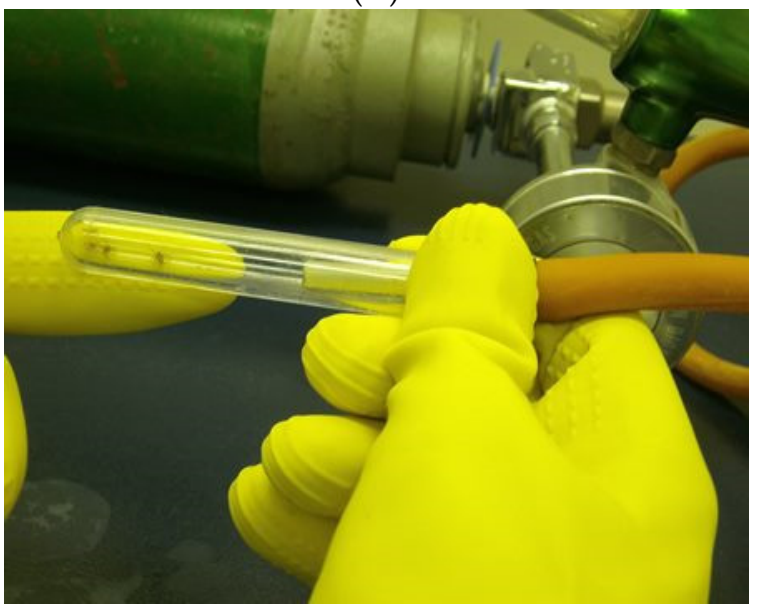

(C)

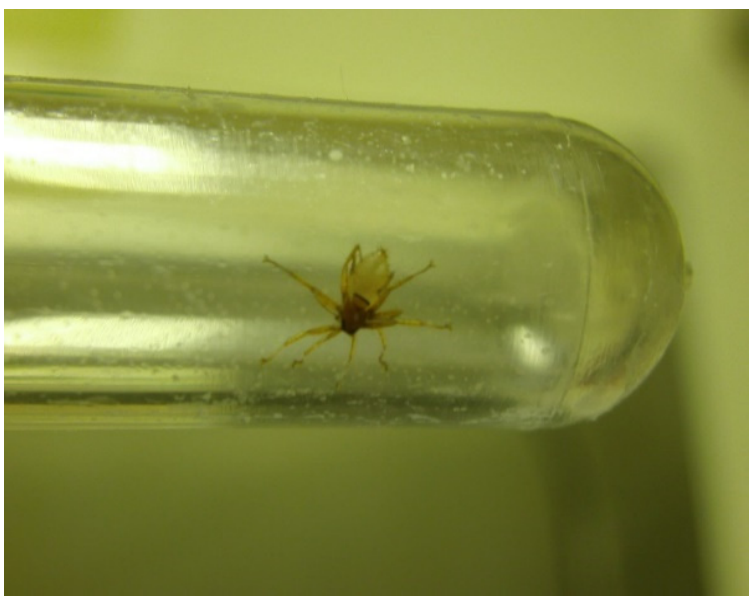

(E)

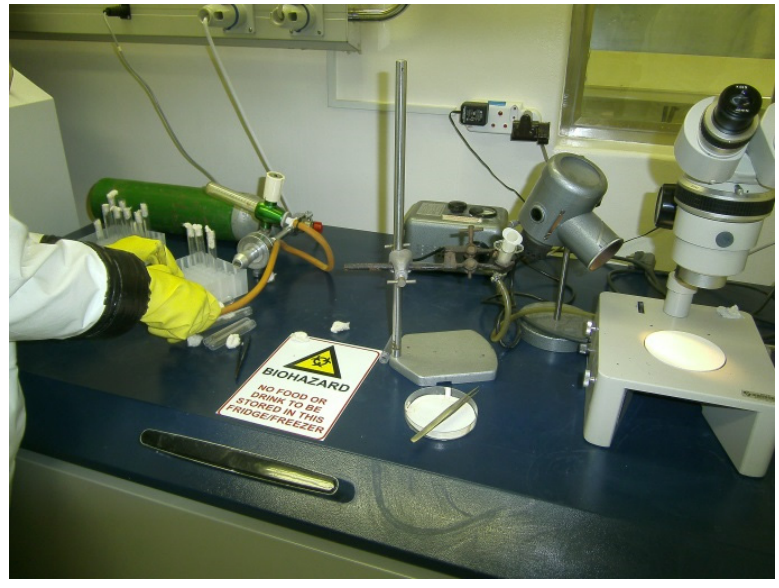

(B)

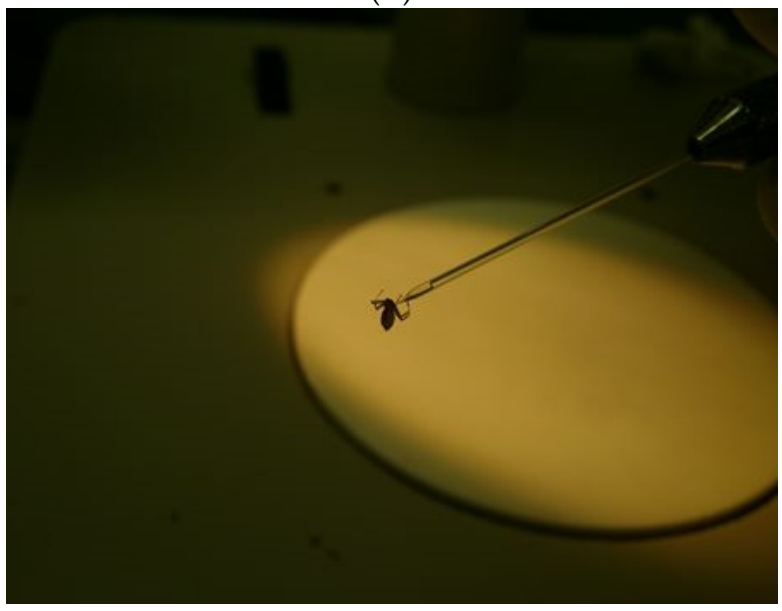

(D)

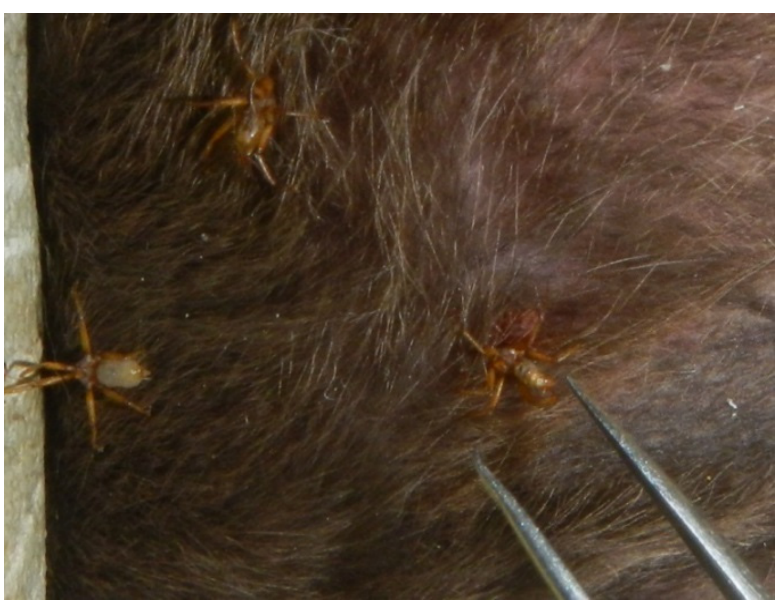

(F)

Figure 8. Bat flies kept in plastic tubes for anaesthesia (A); Stereomicroscope with light source, inoculation equipment, and $\mathrm{CO}_{2}$ cylinder (B). Anaesthesia of flies with $\mathrm{CO}_{2}(\mathbf{C})$; Intra-coelomic inoculation of flies with Marburg virus (MARV) under stereomicroscope (D); Inoculated female bat fly in a glass tube recovering from anaesthesia and inoculation (E). Release of inoculated flies on MARV-seronegative bats (F).

\subsection{Serology}

An indirect enzyme-linked immunosorbent assay (I-ELISA) based on purified recombinant MARV (Musoke) glycoprotein GP antigen (recGP I-ELISA) (Integrated BioTherapeutics, Gaithersburg, MD, USA) was used for the detection of anti-MARV IgG 
antibody in bat sera using a previously described procedure [29]. Briefly, ELISA plates were coated with $100 \mu \mathrm{L} /$ well of stock antigen $(0.6 \mathrm{mg} / \mathrm{mL})$ diluted 1:1500 in PBS pH 7.2 and incubated overnight at $4{ }^{\circ} \mathrm{C}$. Plates were washed three times with PBS pH 7.2 containing $0.1 \%$ Tween-20. The same washing procedure followed each subsequent stage of the assay. Then, the coated plates were blocked with $10 \%$ fat-free milk powder in PBS and incubated for $1 \mathrm{~h}$ at $37^{\circ} \mathrm{C}$. After washing, $100 \mu \mathrm{L} /$ well of the control and test sera diluted 1:100 in PBS containing 2\% milk powder was added to the plates. After $1 \mathrm{~h}$ incubation at $37^{\circ} \mathrm{C}$, plates were washed, and $100 \mu \mathrm{L}$ of a 1:2000 dilution of the anti-bat immunoglobulin-horseradish peroxidase conjugate (Bethyl, Montgomery, AL, USA) was added to each well. After incubation for $1 \mathrm{~h}$ at $37^{\circ} \mathrm{C}$, plates were washed, and $100 \mu \mathrm{L}$ of 2,2'-azino di-ethyl-benzothiazoline-sulfonic acid substrate was added to each well. Plates were incubated in the dark for $30 \mathrm{~min}$ at room temperature. Reactions were stopped by the addition of $100 \mu \mathrm{L} /$ well of $1 \%$ a sodium dodecyl sulphate solution, and optical densities (OD) were measured at $405 \mathrm{~nm}$. The mean OD readings were converted to a percentage of positive (PP) control serum and the cut-off value of $\geq 16.78 \mathrm{PP}$ was used for the interpretations of recGP I-ELISA results [29].

\subsection{Real-Time Quantitative Reverse-Transcription Polymerase Chain Reaction and Virus Isolation}

We used real-time quantitative reverse transcription polymerase chain reaction (qRTPCR) as described previously [28]. Samples with cycle threshold values $\leq 40$ were regarded as positive. RNA copy numbers detected in samples were converted into median tissue culture infectious dose $\left(\mathrm{TCID}_{50}\right)$ genome equivalent [28].

Virus isolation attempted on field-collected bat flies was performed as previously described [75]. Briefly, the wells of 24-well tissue culture plates (Nunc, Roskidle, Denmark) were seeded with Vero E6 cells and grown to 80-90\% confluency in Eagle's minimum essential medium (EMEM, Lonza, Basel, Switzeraland) supplemented with antibiotics (Penicillin/Streptomycin/AmphotericinB, Lonza, Basel, Switzerland) and 10\% foetal calf serum at $37{ }^{\circ} \mathrm{C}$ and $5 \% \mathrm{CO}_{2}$. Culture medium was removed, and the monolayers in individual wells were inoculated with $200 \mu \mathrm{L}$ of ectoparasite homogenate. After one hour adsorption at $37^{\circ} \mathrm{C}$, the inoculum was removed, and fresh EMEM containing antibiotics and $2 \%$ foetal calf serum added. The 24 -well plates were incubated for 14 days, and cytopathic effects (CPE) were monitored. A second and third blind passage was performed for all samples by inoculating and incubating monolayers as described above with $200 \mu \mathrm{L}$ of undiluted supernatant from the preceding passage.

\subsection{Statistical Analysis}

The statistical differences in mean viral load levels in flies fed on MARV-infected bats and in MARV-inoculated flies were calculated using a non-parametric, two-sample Wilcoxon rank (Mann-Whitney) test because of not normal data distribution. Statistical differences in bat fly survival were calculated using Fisher's exact test. Statistical analysis was done using Stata 13 (StataCorp, College Station, TX, USA) and Microsoft Excel (2016). For both analyses, a $p$-value $\leq 0.05$ indicates a statistical significant difference.

\section{Results}

\subsection{Estimation of Infestation Rate of Egyptian Rousette Bats by Bat Flies}

Estimates of infestation rates and the number of bat flies found on ERBs in Matlapitsi Cave were calculated based on two separate collections in November 2016 are given in Table 1. Irrespective of the collection date, sexes, and physiological status of bats, infestation rates by E. africana flies were very high, ranging from $95.2 \%$ to $100 \%$. An average number of flies per bat ranged from $7.0 \pm 6.9$ to $27.3 \pm 24.1$. Infestation was higher on male ERBs, and up to 46 to 67 bat flies could be collected from a single male (Table 1). Despite rather heavy mean infestation rate per bat, all bats sampled appeared healthy. 
Table 1. Infestation rate of Egyptian rousette bats by bat flies at Matlapitsi Cave estimated on two different collection dates in November 2016, South Africa.

\begin{tabular}{|c|c|c|c|c|c|c|}
\hline Date of Capture and Flies Count & No. Bats Captured & No. ERB Females & No. ERB Males & $\begin{array}{c}\text { No. Non-Pregnant } \\
\text { Females without Pups }\end{array}$ & No. Pregnant Females & No. Females with Pups \\
\hline \multicolumn{7}{|c|}{ 2-3 November 2016} \\
\hline Total no. bats captured & 56 & 51 & 5 & $-{ }^{a}$ & - & - \\
\hline Infestation rate $(\%)$ & 98.3 & 98.0 & 100 & - & - & - \\
\hline Mean $\pm \mathrm{SD}^{\mathrm{b}}$ no. flies/bat & $9.8 \pm 8.3$ & $9.0 \pm 6.8$ & $18.0 \pm 16.6$ & - & - & - \\
\hline Range in no. flies/bat & $0-46$ & 0-28 & $5-46$ & - & - & - \\
\hline \multicolumn{7}{|c|}{ 14-15 November 2016} \\
\hline Total no. flies & 556 & 365 & 191 & 158 & 73 & 134 \\
\hline Infestation rate $(\%)$ & 95.2 & 96.4 & 100 & 89.5 & 100 & 95.5 \\
\hline Mean \pm SD no. flies $/$ bat & $9.0 \pm 12.0$ & $7.0 \pm 6.9$ & $27.3 \pm 24.1$ & $8.3 \pm 10.4$ & $5.2 \pm 3.6$ & $6.1 \pm 4.0$ \\
\hline Range in no. flies/bat & $0-67$ & $0-36$ & $1-67$ & $1-36$ & $1-14$ & $1-12$ \\
\hline
\end{tabular}

${ }^{\mathrm{a}}$ No count done; ${ }^{\mathrm{b}}$ Standard deviation. 


\subsection{Field Infection Rate with Marburg Virus in Nycteribiid Bat Flies}

A total of 1653 bat flies collected from ERBs roosting at Matlapitsi Cave from June 2012 to July 2018 were tested for the presence of MARV. Virus isolation was attempted on 273 individual flies collected from March 2013 to March 2014, and the remaining flies were tested by qRT-PCR. Of 1693 bat flies tested, only one $(0.06 \%$; Ct value $=38.71)$, from a single night's collection of 315 specimens ( $0.3 \%$ ) in April 2016, tested positive for the presence of MARV RNA. From 273 flies subjected to virus isolation, 13 isolates were obtained, of which two were identified as a novel fusogenic orthoreovirus and 11 isolates were identified as a novel orthobunyavirus; these findings were reported elsewhere $[75,76]$.

\subsection{Survival and Biology of Bat Flies}

Of the 626 field-collected bat flies, $68(10.9 \%)$ died between the time of collection and the time of their release on captive-bred bats in BSL4 (within approximately 8-10 h, including about $5 \mathrm{~h}$ of road transportation). Dead bat flies were collected into individual microtubes and stored at $-70{ }^{\circ} \mathrm{C}$ until testing. An additional 15 bat flies died after IC inoculation and were discarded. A total of 400 bat flies were released on bats in experiment I (C1-C5; $n=400)$, and 137 bat flies were released on bats in experiment II (C7-C9); 6 ICinoculated bat flies were immediately stored $-70{ }^{\circ} \mathrm{C}$ after inoculation until testing. During the time of experimentation, the average percentage of $\mathrm{RH}$ in two animal isolators housing bat cages was $41.6 \pm 16.3 \mathrm{SD}$ (mean \pm standard deviation) and $35.9 \pm 36.2$, while the average temperature was $20.2 \pm 0.95$ and $21.1 \pm 2$, respectively. The average measurements of humidity and ambient temperatures in animal isolators were within those recorded in Matlapitsi Cave.

The survival rates and the number of bat flies collected for qRT-PCR testing after the release of flies on infected bats and after the release of IC-inoculated bat flies on MARV-seronegative bats are given in Table 2. About $50 \%$ of bat flies fed on infected bats and IC-inoculated bat flies were alive on day 5 PI, and about $15 \%$ were alive on day 22 PI, respectively (Table 2). The survival rates were not significantly different for flies fed on infected bats and for IC-inoculated flies fed on MARV-seronegative bats, on days $3(p=0.878), 12(p=0.898), 15(p=0.730)$, and $22(p=0.674)$ PI (Table 2). There was a significant decrease in the number of flies in both experiments between days 3 and 12 PI $(p<0.001)$, but there was no significant decrease between day 12 and 15 PI ( $p=0.554$ and $p=0.254)$ and day 15 and 22 PI $(p=0.317$ and $p=0.462)$.

Table 2. Survival and number of bat flies collected for laboratory testing (A) after feeding flies on MARV-infected bats and (B) after feeding of MARV-inoculated flies on R. aegyptiacus bats.

\begin{tabular}{|c|c|c|c|c|c|c|}
\hline \multirow{2}{*}{ Flies Fed on Infected Bats } & \multicolumn{5}{|c|}{ Cage No. } & \multirow{2}{*}{$\begin{array}{c}\text { Count/No. Collected } \\
\text { Survival }(\%)\end{array}$} \\
\hline & 1 & 2 & 3 & 4 & 5 & \\
\hline \multicolumn{7}{|c|}{ (A) } \\
\hline Day $^{\mathrm{a}} 0$ & $60^{b}$ & 60 & 60 & 120 & 100 & $400 / 0$ \\
\hline Day 3 & $48 / 1^{c}$ & $42 / 2$ & $44 / 2$ & $\mathrm{nc}^{\mathrm{d}} / 15$ & nc/13 & $\begin{array}{c}134 / 33 \\
134 / 180^{\mathrm{e}}(74.4)\end{array}$ \\
\hline Day 5 & $28 / 0$ & $29 / 0$ & $31 / 0$ & $\mathrm{nc}^{\mathrm{e}} / 25$ & $\mathrm{nc} / 20$ & $\begin{array}{c}86 / 45 \\
93 / 180(51.7)\end{array}$ \\
\hline Day 7 & $\mathrm{nc} / 0$ & $\mathrm{nc} / 7$ & $\mathrm{nc} / 0$ & nc/15 & nc/12 & $\mathrm{nc} / 34$ \\
\hline Day 9 & nc/0 & $\mathrm{nc} / 0$ & nc/0 & $33 / 0$ & $27 / 0$ & $\begin{array}{c}60 / 0 \\
87 / 220(39.5)\end{array}$ \\
\hline Day 12 & $9 / 0$ & $12 / 2$ & $26 / 4$ & $\mathrm{nc} / 0$ & $\mathrm{nc} / 0$ & $\begin{array}{c}47 / 6 \\
(26.1) 47 / 180\end{array}$ \\
\hline Day 15 & $8 / 3$ & $7 / 3$ & $10 / 3$ & $\mathrm{nc} / 8$ & $\mathrm{nc} / 4$ & $\begin{array}{c}25 / 21 \\
31 / 180(17.2)\end{array}$ \\
\hline Day 22 & $2 / 2$ & $4 / 0$ & $8 / 0$ & $12 / 6$ & $9 / 4$ & $\begin{array}{c}35 / 12 \\
56 / 400(14.0)\end{array}$ \\
\hline Day 29 & 0 & $2 / 2$ & $5 / 5$ & $8 / 8$ & $2 / 2$ & $\begin{array}{c}17 / 17 \\
29 / 400(7.3)\end{array}$ \\
\hline
\end{tabular}


Table 2. Cont.

\begin{tabular}{|c|c|c|c|c|}
\hline \multirow{2}{*}{ Inoculated Flies Fed on Bats } & \multicolumn{3}{|c|}{ Cage No. } & \multirow{2}{*}{$\begin{array}{c}\text { Count/No. Collected } \\
\text { Survival }(\%)\end{array}$} \\
\hline & 7 & 8 & 9 & \\
\hline \multicolumn{5}{|c|}{ (B) } \\
\hline Day ${ }^{\mathrm{f}} 0$ & $24^{b}$ & 30 & 83 & 137 \\
\hline Day 3 & $\mathrm{nc} / 0$ & $\mathrm{nc} / 0$ & $63 / 0$ & $\begin{array}{c}63 / 0 \\
63 / 83(75.9)\end{array}$ \\
\hline Day 7 & $10 / 1$ & $14 / 1$ & $43 / 5$ & $\begin{array}{c}67 / 7 \\
67 / 137(48.9)\end{array}$ \\
\hline Day 12 & $5 / 0$ & $8 / 0$ & $24 / 0$ & $\begin{array}{c}37 / 0 \\
37 / 137(27.0)\end{array}$ \\
\hline Day 15 & nc & nc & $16 / 16$ & $\begin{array}{c}16 / 16 \\
16 / 83(19.3)\end{array}$ \\
\hline Day 22 & $2 / 0$ & $3 / 0$ & $0 / 0$ & $\begin{array}{c}21 / 0 \\
21 / 137(15.3)\end{array}$ \\
\hline
\end{tabular}

${ }^{\mathrm{a}}$ Day post infection of bats with Marburg virus (MARV); ${ }^{\mathrm{b}}$ No. of bat flies released on day 0 post inoculation in each experimental bat cage; ${ }^{\mathrm{c}}$ No. of bat flies counted and collected for testing; ${ }^{\mathrm{d}}$ Count not done; ${ }^{\mathrm{e}}$ Survival rates on different days post inoculation; ${ }^{\mathrm{f}}$ Day post infection of flies with MARV. Note: Survival rates on different days post inoculation were calculated using the following formula: percentage survival $=$ (no. flies on day of counting plus no. flies collected in preceding day of count/total no. of flies released) $\times 100$. For example, the survival rate of flies in Cages 1-3 on day 5 post inoculation is $51.7 \%$ : for day 5 , the count of flies is 86 , the number of flies collected on preceding count day is 5 , the total number of flies released in C1-C3 was 180; thus, $(93 / 180) \times 100=51.7 \%$. This calculation is based on the arbitrary assumption that at least flies collected during the preceding count would survive until the next count.

While we did not mark flies to monitor their movement between bats within the same cage, judging from the changing infestation numbers observed on individual bats on a daily basis and due to the close roosting and social behaviour of the bats, it can be assumed that active movement was taking place.

F1 pupae were deposited regularly (Figure 9), with the first seen the day after release of flies in C1-C8. Most pupae were deposited on the wooden roosting substrate, but occasionally, they were also deposited on the walls of cages. Over a period of 43 days of experiment I, 216 pupae were counted, of which 96 were collected for testing (Table 3). Over a period of 38 days of experiment II, 179 pupae were counted, of which 85 were collected for testing (Table 3). The first emergence of F1 bat flies was noted in C1-C8 around 22 days PI. Of the $120 \mathrm{~F} 1$ emerged flies, 100 were collected for testing (Table 3).

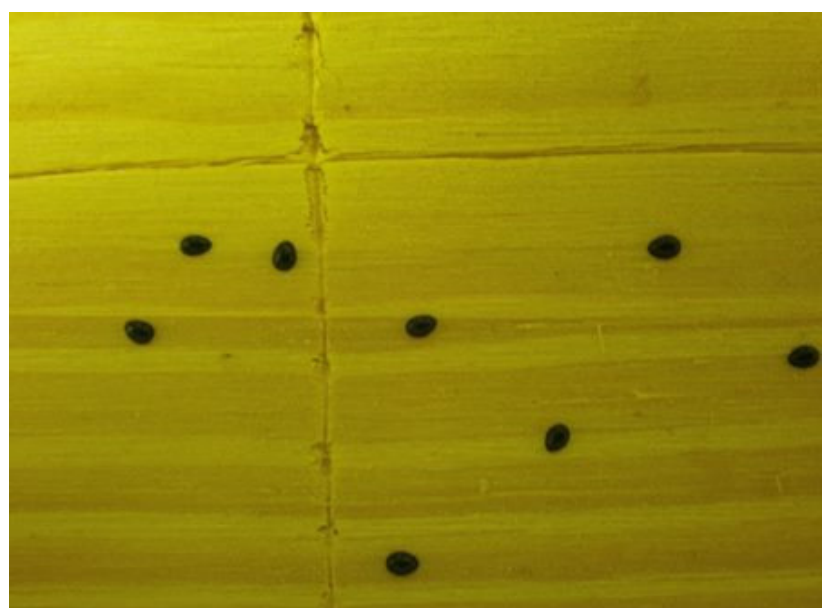

(A)

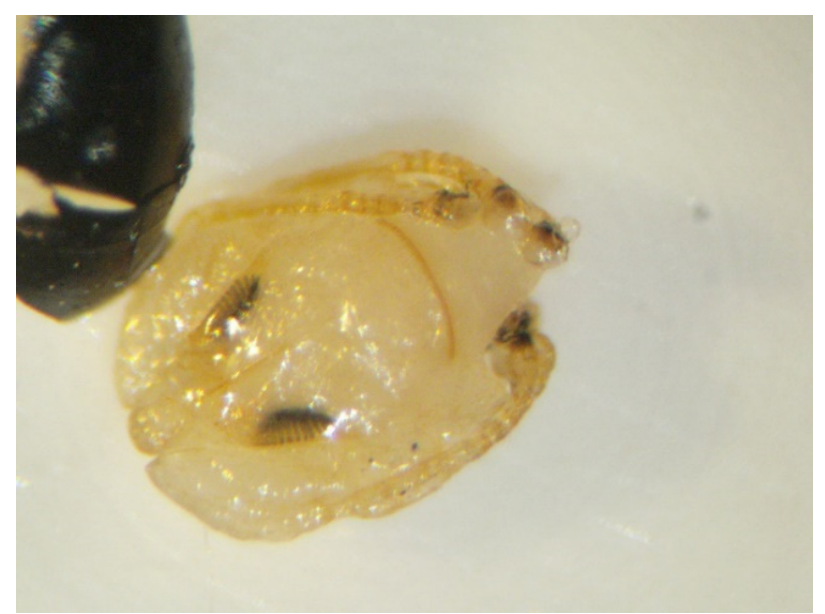

(B)

Figure 9. Bat fly pupae deposited on wooden plank (A). Emerging bat fly (B). 
Table 3. Number of F1 generation pupal and adult bat flies counted and collected for testing in cages housing flies fed on subcutaneously (SC) inoculated bats (C1-C5) with Marburg virus (MARV) and in cages (C6-C8) housing flies administered MARV by intra-coelomic inoculation (IC).

F1 Pupal and Adult Flies

Day after SC Inoculation Cages 1-5

\begin{tabular}{cccccccccccc}
\hline & 3 & 5 & 7 & 9 & 12 & 15 & 22 & 29 & $36-43$ & Total \\
\hline No. pupae & 13 & 28 & 38 & 37 & 31 & 58 & 34 & 37 & 20 & 216 \\
New & 13 & 15 & 21 & 12 & 6 & 33 & 10 & 3 & 7 & 120 \\
Collected & 0 & 11 & 13 & 12 & 6 & 34 & 0 & 0 & 20 & 96 \\
No. flies Collected & 0 & 0 & 0 & 0 & 0 & 0 & 5 & 16 & 25 & 46 \\
\end{tabular}

Day after Post IC Inoculation Cages 7-9

\begin{tabular}{ccccccccccc}
\hline & 3 & 5 & 7 & 9 & 12 & 15 & 22 & 29 & $33-38$ \\
\hline No. pupae & 30 & 55 & 68 & 72 & 64 & 65 & nc $^{\text {a }}$ & 51 & 25 & 179 \\
New & 30 & 25 & 13 & 4 & 5 & 11 & nc & 4 & 2 & 94 \\
Collected & 0 & 0 & 0 & 13 & 10 & 9 & 0 & 28 & 25 & 85 \\
No. flies Collected & 0 & 0 & 0 & 0 & 0 & 0 & 15 & 48 & 17 & 74 \\
\end{tabular}

${ }^{a}$ Not count done.

\subsection{Horizontal Transmission}

3.4.1. Oral Susceptibility of Bat Flies to MARV following Feeding on Viremic Bats and Attempted Transmission of MARV by Bat Flies from Viremic Bats to in Contact Bats

All bats remained clinically well, maintained normal food uptake, and no abnormal behavioural or clinical disease were recorded. None of the bats sustained apparent injury during the duration of the experiments. The first seroconversions were detected on day 7 after SC inoculation, and by day 15, all the infected bats in C1-C6 became MARVseropositive. The highest levels of anti-MARV IgG level were recorded 2-3 weeks after SC inoculation, which was followed by a decrease on day 29. None of the eight in-contact control bats in C1-C3, and C6, seroconverted (Figure 10).

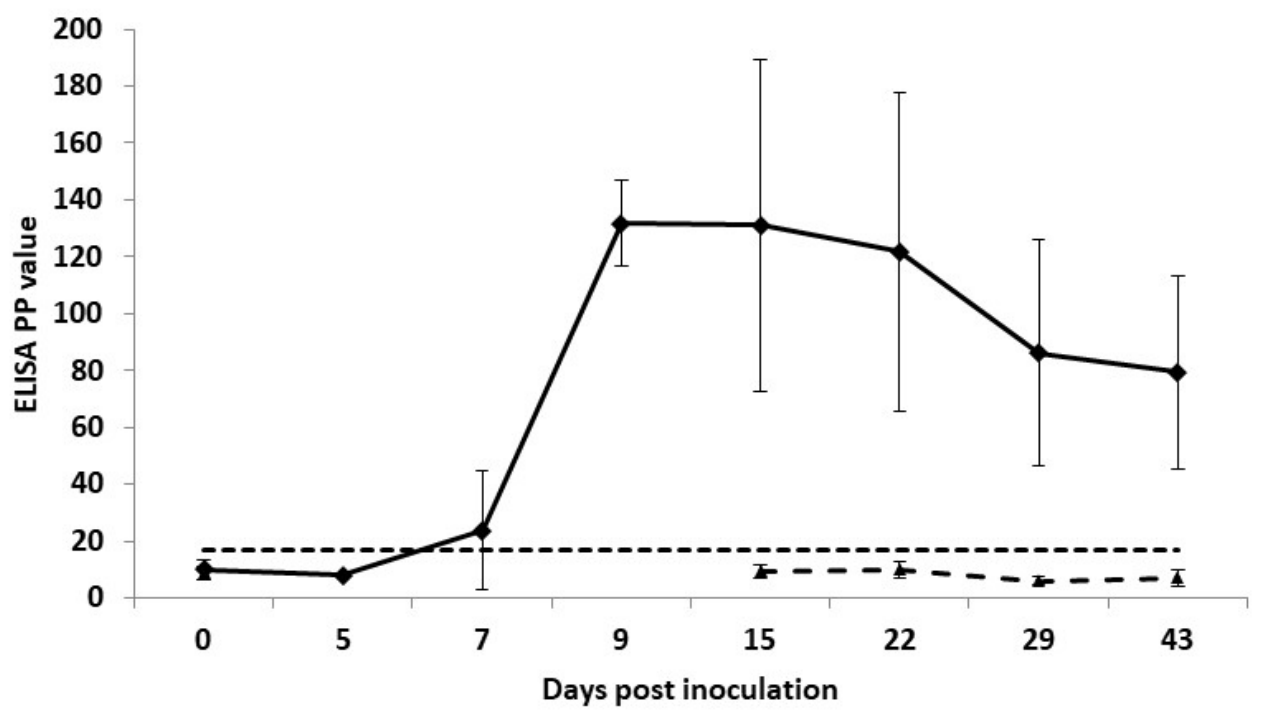

$\longrightarrow$ Infected bats $\quad \leftarrow$ In-contact control bats ----ELISA cut-off

Figure 10. Mean IgG antibody levels (with standard deviations) in Egyptian fruit bats inoculated subcutaneously with Marburg virus (MARV) and in-contact MARV-seronegative bats artificially infested with bat flies. Results for anti-MARV IgG antibody by enzyme-linked immunosorbent assay (ELISA) are shown as the percentage positivity (PP) relative to positive internal control serum; the dotted line without markers denotes an ELISA cut-off value of 16.78 PP [28]. 
All bats in C1-C6 became viremic within 3-5 days post inoculation (PI), with a mean $( \pm \mathrm{SD})$ peak viremia of $10^{4.6 \pm 0.61} \mathrm{TCID}_{50} / \mathrm{mL}$ on day $5 \mathrm{PI}$; most bats cleared detectable viremia by day 9 PI (Table 4 ). At the peak of viremias, there was no statistical difference $(p=0.260)$ in their levels between MARV-infected/infested bats and MARV-infected noninfested bats. Viremia levels in individual bats ranged from $10^{1.84}$ (day 9 PI) to $10^{5.0}$ (day 5 PI) $\mathrm{TCID}_{50} / \mathrm{mL}$.

Table 4. Experiment 1. Quantitative reverse-transcription PCR (RT-PCR) results in captive-bred Rousettus aegyptiacus inoculated subcutaneously with Marburg virus (MARV) (A) and in bat flies fed on MARV-inoculated bats (B).

\begin{tabular}{|c|c|c|}
\hline Days Post Inoculation ${ }^{a}$ & $\begin{array}{l}\text { Number of Bats Tested/Positive } \\
\text { (\% Viremic Bats) }\end{array}$ & $\begin{array}{c}\text { Mean } \log _{10} \mathrm{TCID}_{50} \mathrm{~b} \pm \mathrm{SD}^{\mathrm{c}} \\
\qquad / \mathrm{mL} \text { Blood }\end{array}$ \\
\hline \multicolumn{3}{|c|}{$(\mathbf{A})$} \\
\hline 3 & $11 / 13(84.6)$ & $3.25 \pm 0.63$ \\
\hline 5 & $11 / 11(100)$ & $4.06 \pm 0.61$ \\
\hline 7 & $4 / 9(44.4)$ & $2.05 \pm 0.57$ \\
\hline 9 & $2 / 11(27.3)$ & $1.86 \pm 0.03$ \\
\hline 12 & $0 / 12$ & 0 \\
\hline $15-22$ & $0 / 23$ & 0 \\
\hline Days Post Inoculation ${ }^{d}$ & $\begin{array}{l}\text { Number Bat Flies Tested/Positive } \\
\text { (\% Flies Positive) }\end{array}$ & Mean $\log _{10} \mathrm{TCID}_{50} \pm$ SD/Fly \\
\hline \multicolumn{3}{|c|}{ (B) } \\
\hline 3 & $31 / 0(0)$ & \\
\hline 5 & $25 / 3(12.0)$ & $0.25 \pm 0.08$ \\
\hline 7 & $39 / 12(30.8)$ & $2.01 \pm 1.24$ \\
\hline 9 & $29 / 0$ & \\
\hline $12-15$ & $47 / 0(0)$ & \\
\hline $21-29$ & $25 / 0(0)$ & \\
\hline $36-43^{\mathrm{e}}$ & $20 / 0(0)$ & \\
\hline \multicolumn{3}{|c|}{$\begin{array}{l}\text { a Cumulative qRT-PCR results (Experiment I-bat cages C1-C6) in } 27 \text { Rousettus aegyptiacus bats inoculated } \\
\text { subcutaneously with Marburg virus (MARV) on different days post infection; }{ }^{b} \text { MARV RNA copy numbers } \\
\text { detected in samples converted into median tissue culture infectious dose (TCID }{ }_{50} \text { ) genome equivalents [28]; }{ }^{c}\end{array}$} \\
\hline
\end{tabular}

We did not determine the blood meal size of bat flies in our study, and this information is not available in the literature. However, engorged flies with visible blood were seen on bats and during their collection by the naked eye. The size of adult E. africana is $2.5-3.0 \mathrm{~mm}$, of which one-third constitutes the abdomen [80]. Assuming the latter is approximately half a sphere, the volume of the abdomen would be no more than $2.1 \mathrm{~mm}^{3}$ using the following formula: $2 / 3 \prod \mathrm{r}^{3}$.

Various species of hematophagous arthropods can ingest a blood meal of up to one to three times their body size. For example, Zeng et al. [81] estimated that the mean $( \pm \mathrm{SD})$ size of a blood meal ingested by Ornithodoros turicata nymphs is $31.5 \pm 16.8 \mathrm{mg}$, representing a 3.5-fold increase from their respective unfed weights of $12.6 \pm 2.5 \mathrm{mg}$. Adult male Glossina morsitans with an estimated mean body weight of $22.0 \pm 2.2 \mathrm{mg}$ [82] ingest mean blood meal size of $26.1 \pm 0.9 \mathrm{mg}$ [83]. Males and females of unfed pigeon fly (Pseudolynchia canariensis) with a mean body weight of $4.80 \pm 0.13 \mathrm{mg}$ and $5.03 \pm 0.94 \mathrm{mg}$ can take on average $6.5 \mathrm{mg}$ and $5.5 \mathrm{mg}$ of blood meal, respectively [84]. However, the range of blood meal size can vary substantially, depending on the individual flies [81-84]. Pseudolynchia canariensis is approximately two times bigger than E. africana. Taking into account this information and the estimated size of E. africana's abdomen, we extrapolate that the average size of blood meal volume for this species would be $\approx 3 \mu \mathrm{L}$, corresponding to $\approx 3 \mathrm{mg}$. We use the estimated blood meal size for the interpretation of virological results in bat flies fed on viremic bats. 
The mean viral load in bat flies fed on viremic bats ranged from $10^{0.25 \pm 0.08}$ to $10^{2.01 \pm 1.24}$ $\mathrm{TCID}_{50} /$ fly (Table 4 ), with a concentration of MARV per individual fly ranging from $10^{0.16}$ to $10^{3.32}$. There was a significant statistical difference $(p=0.042)$ between viral loads recorded in flies on day 5 and day 7 PI with mean viral load in flies on day 7 PI being $8 \times$ higher compared to that on day 5 PI (Table 4). Flies with mean viral loads $\geq 10^{2.0}$ would have to ingest $\geq 1 \mu \mathrm{L}$ of viremic blood having $\geq 10^{5.0} \mathrm{TCID}_{50} / \mathrm{mL}$ of the virus. This indicates that in most flies, viral loads represent the amount of the virus taken from viremic bats in the estimated size of the blood meal and thus does not evidence MARV replication. Four $(40 \%)$ out of 10 flies tested on day seven PI had MARV load $>10^{3.0} \mathrm{TCID}_{50}$. Would MARV replicate in those flies, they would have to take $>10 \mu \mathrm{L}$ of $\geq 10^{5.0} \mathrm{TCID}_{50} / \mathrm{mL}$ of viremic blood, which is about three times more than the volume of the estimated blood meal size.

Flies feed regularly on their hosts, and the higher concentration of MARV in flies recorded on day 7 PI might be due to accumulation of the virus from the previous blood meals. It could be also that some level of replication was still taking place in the bats' blood cells upon uptake by flies or/and that we underestimated the blood meal size. Even though some level of transient MARV replication could take place in flies, e.g., the cells of the midgut, following feeding on viremic bats, it did not result in disseminated infection, as evidenced by results in flies collected from bats on days 9-43 PI; all tested negative for MARV RNA (Table 4).

The lack of susceptibility to oral infection with MARV upon feeding on viremic bats and the incapacity of flies to horizontally vector MARV is supported by the fact that none of the MARV-seronegative in-contact bats developed viremia or seroconverted within 43 days, despite the active movement of flies between infected and control bats.

3.4.2. Susceptibility of Bat Flies to MARV following IC Inoculation and Attempted Transmission of MARV from IC Inoculated Flies to Bats

All bat flies tested on day 0 (immediately after inoculation) and day 7 after IC inoculation were positive for MARV RNA but negative on days 12-38 post IC inoculation (Table 5). There was statistically no significant difference in MARV concentration on days 0 and 7 after IC inoculation $(p=0.474)$, and viral loads were consistent with that of the inoculum. None of the 18 MARV-seronegative bats became viremic or seroconverted within 38 days after infestation with MARV-inoculated flies.

Table 5. Experiment 2. Quantitative reverse-transcription PCR (RT-PCR) results in bat flies (Eucampsipoda africana) inoculated by intra-coelomic administration of Marburg virus (MARV).

\begin{tabular}{|c|c|c|}
\hline $\begin{array}{l}\text { Days Post } \\
\text { Inoculation a }\end{array}$ & $\begin{array}{c}\text { Number } \\
\text { Bat Flies Tested/Positive (\% Positive) }\end{array}$ & Mean $\log _{10} \mathrm{TCID}_{50}{ }^{\mathrm{b}} \pm \mathrm{SD} / \mathrm{Fly}$ \\
\hline 0 & 6/6 (100) & $1.7 \pm 0.54$ \\
\hline 7 & $10 / 10(100)$ & $1.35 \pm 1.06$ \\
\hline 12 & $16^{d} / 0(0)$ & \\
\hline 21 & $10 / 0(0)$ & \\
\hline $31-38^{\mathrm{e}}$ & $100 / 0(0)$ & \\
\hline
\end{tabular}

\subsection{Vertical Transmission}

Of the F1 generation 181 pupae and 100 flies collected during experiments I and II (Table 3), all tested negative by RT-PCR, which indicates the biological incapacity of bat flies to transmit MARV vertically. 


\section{Discussion}

Understanding of filoviruses maintenance in natural host systems is important in defining the mechanisms of their transmission among reservoirs and those triggering spillover outside their primary ecological habitats. This knowledge will help develop science-based risk reduction strategies and public health messaging. Experimental studies seem to confirm that clinical, virological, and immunological responses are consistent with ERB being a reservoir host for MARV [28-33]. Several portals of entry of MARV have been postulated. Experimental SC inoculation of ERBs with MARV, as a proxy for mechanical transmission through skin injury, has been shown to lead to disseminated infection of alimentary, respiratory, and reproductive organs $[29,30]$, but horizontal or vertical transmission resulting from this route of infection has not yet been confirmed. The unsuccessful infection of ERBs with MARV via the oronasal route [28] and absence of aerosol transmission or infected nasal secretions, despite the presence of low levels of MARV in ERB lungs [29], argues against a primary role for transmission via the respiratory route.

Currently available experimental data point to the possibility of oral and/or faecal route of MARV transmission [29-32], which could explain why primary human MVD cases are often associated with bat habitats in the absence of direct contact through bites, collisions, or scratches [2]. While Schuh et al. [32] seems to demonstrate in-contact bat-tobat transmission, the delay in viremia and seroconversion in naïve contact ERBs is difficult to explain. Persistent infection in one or more of the infected bats might be one explanation, but the mechanisms that presumably triggered virus reactivation and acute infection after a prolonged incubation period would require further studies. The postulated prolonged MARV incubation period of at least 7 months in ERBs following horizontal transmission of the virus [32] seems to be not supported by findings in ERBs under natural settings. Namely, not only there is a rapid increase in MARV seropositivity in juvenile bats shortly after the waning of maternal immunity [39,74], but shedding of the virus in saliva and faeces is very low [74]. These results suggest that faecal-oral bat-to-bat transmission might be not a sustainable mechanism for the maintenance and perpetuation of marburgviruses. Furthermore, MARV inoculation into the oral cavities of naïve ERBs did not result in infection [28].

Blood-sucking flies of the families Nycteribiidae and Streblidae (Diptera: Hippoboscoidea) represent ectoparasites that are highly associated with bats $(59-62,78,80)$. Their role in the ecology of filoviruses has been postulated for a long time [55] but never studied experimentally. To date, nearly 40 species of nycteribiid and 32 of streblid bat flies have been documented in Africa $[78,85]$. However, knowledge of bat flies that parasitise cave-dwelling chiropterans is limited. Entomological surveys conducted in Gabon demonstrated that the bat fly species Nycteribia schmidlii scotti and Penicillidia fulvida were strongly associated with $M$. inflatus, while E. africana was preferentially associated with R. aegyptiacus [68]. Infestation rates for ERBs in this study varied significantly throughout the year and between caves (from 29.4 to $91.5 \%$ ), but the mean number of E. africana flies per infected bat (2.66) remained stable [68]. Nycteribiid host preference was demonstrated in Madagascar and the Comoros, where E. madascarensis and E. theodori were specifically associated with local frugivorous Rousettus species [59,62]. In our study, both infestation rates of ERB's Matlapitsi population as well as the mean number of E. africana flies per bat were higher than those reported from Gabon [68]. Bat species that are roosting in more permanent, enclosed structures, such as Mahune Cave, are more likely to carry heavier parasite loads and to harbour more species of flies [86].

The detection of significant viremia in experimentally infected ERBs, host-specificity of the haematophagous nycteribiids for ERBs, and their ability to take multiple blood feeds make a strong case for a natural, feral transmission cycle for MARV. All that is still required is the development of a MARV infection in the midgut and haemocoel of the bat fly, with dissemination to the salivary glands and into the saliva for successful transmission to receptive bats. Recently, viruses other than marburgviruses have been isolated from 
nycteribiids, including E. africana $[67,75,76]$, demonstrating their potential in vectoring pathogens.

The successful infection of a hematophagous insect by a pathogen and its subsequent replication and dissemination to enable per-oral transmission during feeding is dependent on a number of factors including the vector genotype, environment, and viral pathogen, which are all interlinked and affect vector competence and vector capacity [87]. Vector competence is the ability of a vector to support pathogen infection, replication, dissemination, and transmission [88]. Vectorial capacity refers to the ability of the vector population to transmit pathogen, and it incorporates host preference, biting rates, survivorship, vector competence, and extrinsic incubation period (time from ingestion to transmission) that are subjected to environmental modifications [88]. One of the most important factors affecting vectorial capacity is the temperature, which impacts on immature vector developmental stages, the number of generation produced, and consequently the size of the adult population [89]. Temperature also significantly affects extrinsic incubation and virogenesis [88-91]. A number of genetically driven factors such as innate immunity and tissue replication and escape barriers need to be overcome by an arbovirus, including the midgut infection barrier, midgut escape barrier, salivary gland infection barrier, and salivary gland escape barrier. Genetic factors influencing vector competence can vary widely between vector species, and only specific arbovirus species are adapted to overcome these barriers successfully [89,92]. Hardy et al. [93] proposed a number of steps for a productive arbovirus infection to occur in a vector, including the initiation of infection in the midgut, dissemination from the midgut to secondary tissues, infection of salivary glands (and sometimes reproductive tissues for vertical transmission to offspring), and finally release of the virus into saliva, which is a source of horizontal transmission to an uninfected vertebrate host. While all these variables could not be investigated in our study, the results obtained strongly suggest that bat flies do not support MARV replication, both following the natural ingestion of infectious viremic blood and following an artificial inoculation.

Relatively little is known about the life history and reproductive biology of bat flies, and detailed information regarding the life cycle of E. africana, specifically, is not available. Nonetheless, the characteristics of the life cycle and breeding biology of $E$. africana observed in our study generally resembles what is currently known. These include the following: (1) deposition site (within the confines of the bat's roosting environment); (2) deposition of a single pupa on the substrate; (3) 3-4 weeks (average 23 days) for the emergence of teneral adults from pupa; (4) locating and colonising a host by newly emerged flies; and (5) time interval between successive depositions of pupae of about 10 days [94-96]. Due to the time limitation of our experiment and sampling schedule, the exact life span of E. africana could not be determined, but it appears to correspond to that estimated for other species of bat flies, E. sundaica and Basilia hispida $[95,97]$.

The mean temperature ranges during the housing of bats and ectoparasites under BSL4 environmental conditions were within those recorded at Mahune Cave where we sourced both bats and ectoparasites for this study, but the mean percentage of $\mathrm{RH}$ was lower. The environment of an ectoparasite extends from its immediate environment such as the host itself to the surrounding ecosystem in which the host lives, including anthropogenic and climatic conditions [98]. The roosting biology of bats influences the quality and quantity of parasitism by bat flies [99-101], which in turn might influence the likelihood and capacity of vectoring pathogens. From the point of vertical transmission, it should be noted that pupation takes place off the host, in the bat's roost, and it lasts a few weeks. This means that bat flies spend possibly up to one-third of their life off the host and in the immediate roosting environment, mainly as pupae [101]. During this time, both the nature of the roosting substrate and temperature might influence the replication of a pathogen. These variables and resulting potential limitations could not be addressed, but the full life cycle of E. africana was observed in our study. This indicates that the provided environmental conditions suitably mimicked natural settings, and thus, the results obtained likely reflect 
on the true inability of flies to support MARV replication and consequently the lack of capacity for either horizontal or vertical transmission.

Of 1693 field-collected bat flies, one was positive by qRT PCR but, interestingly, this fly was from a single night collection in April 2016 of 315 specimens at Matlapitsi Cave in South Africa. While the very low field infection rate seems to additionally support experimental findings that bat flies do not play a significant role in the transmission and enzootic maintenance of MARV, our study was not designed to determine the prevalence of MARV infection in the Matlapitsi nycteribiid population. However, it is worth noting that the one positive specimen was collected during the time of the year that coincides with a significantly higher seasonal transmission of MARV in the Matlapitsi ERB population $[39,74]$.

The detection of MARV in bat flies in our study, following feeding on viremic bats up to 7 days PI, might have important ramifications in the context of the postulated oral mechanism of MARV transmission [30,32]. Although peak viremias in both sylvan and experimentally infected bats tend to be rather low and of moderate duration [28-32], the high consumption rates of ectoparasites [102] coupled with the high density and roosting behaviour of Rousettus bats, regular, multiple blood feeds by bat flies, and the extent of time spent by bat flies on ERBs might result in increased exposure to the virus. In has been estimated that the mean number of nycteribiid flies consumed by an adult Madagascar fruit bat (Rousettus madagascariensis) during auto- and allo-grooming was 37 daily. When this number was extrapolated on the estimated number of adult Rousettus bats at the roost site in the Grotte des Chauves-souris, d'Ankarana National Park in Madagascar, the projected daily consumption rate was 57,905 ectoparasites daily [102]. The consumption of contaminated ectoparasites could provide the mechanism for oral MARV transmission. In addition, virus transfer might also take place through the contamination of skin and mucosal membranes when contaminated ectoparasites are squashed during grooming (scratching or licking the body and wing phalanges), eating, biting or fighting, and via contaminated mouthparts during feeding.

In the present study, attempts to infect bat flies by feeding on viremic bats and by artificial inoculation were unsuccessful. However, one has to consider some of the limitations of this first vector competence study, including the potential impact of the dose of inoculum used, the source of the virus, environmental conditions, and the numbers of flies tested. The results from this preliminary study seem to demonstrate that bat flies do not act as biological vectors of MARV. However, considering that bat flies can carry contaminated blood following feeding on viremic bats, their potential role in mechanical transmission cannot be ruled out and would require further investigation. The eating of flies engorged with MARV-contaminated blood by bats with abrasions of their oral cavities-or direct contact with other damaged mucous membranes and/or skin with contaminated flies' blood or indirectly via contaminated fomites-might result in the inoculation of MARV. The inoculation of ERBs via the SC route results in MARV replication in various tissues [28-33]. In our study, none of the bats sustained apparent mucous membranes and/or skin injury or suffered due to mucous and skin disorders during the experiments. However, biting and fighting among bats resulting in mucous membrane and skin injury are observed under natural settings [29].

The Matlapitsi Cave in South Africa is one of many African ecological niches for highly biodiverse mammals and ectoparasites. The multispecies roosting behaviour with potentially highly specific host-parasite interactions might govern transmission cycles of bat fly-associated pathogens. Understanding these networks requires systematic and long-term investigations. To our knowledge, our experimental vector competence work described here is the first to demonstrate the successful colonisation and breeding of bat flies on ERBs and IC inoculation of bat flies under BSL4 conditions. The host-parasite model established here constitutes a potentially valuable research resource for investigating the role of bat ectoparasites in transmitting zoonotic pathogens of public health importance. 
Supplementary Materials: The following are available online at https://www.mdpi.com/article/10 $.3390 / v 13112226 / s 1$, Video S1: The release of inoculated flies on bats in BSL4.

Author Contributions: J.T.P.: conceptualisation, supervision, project administration, methodology, field and experimental work, validation, data curation, analysis and interpretation, funding acquisition, and writing original draft; P.J.v.V.: methodology, field and experimental work, data curation, analysis and interpretation, and review and editing; N.S.: methodology, field and experimental work data curation, analysis and interpretation, and review and editing; W.M.: methodology, field work, funding acquisition, and review and editing; A.K.: methodology, field and experimental work, analysis and interpretation, and review and editing. All authors have read and agreed to the published version of the manuscript.

Funding: The project was funded by grants awarded to: Janusz T. Paweska (CDC Global Disease Detection program, GDD 5U19 GH000571-05/96667; Poliomyelitis Research Foundation, PRF 2017 Grant No. 16/20) and Wanda Markotter (Department of Science and Innovation administered by the National Research Foundation South African Research Chair Grant UID 91496, 92524 and 98339).

Institutional Review Board Statement: This study was carried out in strict accordance with the recommendations of the South African National Standards for the Care and Use of Animals for Scientific Purposes (SANS 10386:2008). The protocols for capturing, field sampling, and transport of ERBs and samples collected from this species was approved by the National Health Laboratory Service Animal Ethics Committee (AEC 137/12), University of Pretoria Animal Ethics Committee (EC054-14), Department of Economic Development, Environment \& Tourism: Limpopo Province Directorate: Wildlife Trade and Regulation Permit (CPM 006806), and the South African Department of Agriculture, Forestry and Fisheries (Section 20 approval 12/11/1/1/8). Ethics approval for the colonisation and experimental infection of ERB with MARV was granted from the National Health Laboratory Service Animal Ethics Committee (AEC 136/12, AEC 139/13) as well as from the University of Pretoria Animal Ethics Committee (EC056-14, H018-16). Ethics approval for experimental MARV transmission study by nycteribiid flies in ERB was obtained from the National Health Laboratory Service Animal Ethics Committee (AEC 147/16; 147/16/A).

Informed Consent Statement: Not applicable.

Data Availability Statement: The data presented in this study are available within the article.

Acknowledgments: The authors would like to thank the staff of the Centre for Emerging and Zoonotic Disease NICD/NHLS and of the Centre for Viral Zoonoses, Department of Medical Virology, Faculty of Health Sciences, University of Pretoria for helping with the field and laboratory technical aspects of the work. We would also like to thank the NICD/NHLS BSL4 biosafety staff.

Conflicts of Interest: The authors declare no conflict of interest. The funders had no role in the design of the study; the collection, analyses, or interpretation of data; in the writing of the manuscript; or the decision to publish the results. Grant holders acknowledge that the opinions, findings, and conclusions or recommendations expressed in any publication generated by GDD and NRFsupported research are those of the authors and that the GDD and NRF accept no liability whatsoever in this regard.

\section{References}

1. Amarasinghe, G.K.; Aréchiga Ceballos, N.G.; Banyard, A.C.; Basles, C.F.; Bavari, S.; Bennett, A.J.; Blasdell, K.R.; Brise, T.; Bukreyew, A.; Caì, Y.; et al. Taxonomy of the order Mononegavirales: Update 2018. Arch. Virol. 2018, 163, 2283-2294. [CrossRef]

2. Amman, B.R.; Swanepoel, R.; Nichol, S.T.; Towner, J.S. Ecology of filoviruses. Curr. Top. Microbiol. Immunol. $2017,411,23-61$.

3. World Health Organization. Marburg Virus Disease-Uganda. 25 October 2017. Available online: http://www.who.int/csr/ don/25-october-2017-marburg-uganda/en/ (accessed on 28 December 2017).

4. World Health Organization. West African's First-Ever Case of Marburg Virus Disease Confirmed in Guinea. Available online: http:/ / www.afro.who.int (accessed on 9 August 2021).

5. Towner, J.S.; Pourrut, X.; Albariño, C.G.; Nkoque, C.N.; Bird, B.H.; Grard, G.; Ksiazek, T.G.; Gonzalez, J.P.; Nichol, S.T.; Leroy, E.M. Marburg virus infection detected in a common African bat. PLoS ONE 2007, 2, e764. [CrossRef]

6. Changula, K.; Kajihara, M.; Mori-Kajihara, A.; Eto, Y.; Miyamoto, H.; Yoshida, R.; Shigeno, A.; Hang'ombe, B.; Qiu, Y.; Mwizabi, D.; et al. Seroprevalence of filovirus infection of Rousettus aegyptiacus bats in Zambia. J. Infect. Dis. 2018, 218, S312-S317. [CrossRef]

7. Amman, B.R.; Bird, B.H.; Bakar, I.A.; Bangura, J.; Schuh, A.J.; Johnny, J.; Sealy, T.K.; Conteh, I.; Koroma, A.H.; Foday, I.; et al. Isolation of Angola-like Marburg virus from Egyptian rousette bats from West Africa. Nat. Commun. 2017, 11, 510. [CrossRef] 
8. Gear, J.S.; Cassel, G.A.; Gear, A.J.; Trappler, B.; Clausen, L.; Meyers, A.M.; Kew, M.C.; Bothwell, T.H.; Sher, R.; Miller, G.G.; et al. Outbreak of Marburg virus disease in Johannesburg. Br. Med. J. 1975, 29, 489-493. [CrossRef] [PubMed]

9. Towner, J.S.; Khristova, M.L.; Sealy, T.K.; Vincent, M.J.; Erickson, B.R.; Bawiec, D.A.; Hartman, A.L.; Comer, J.A.; Zali, A.R.; Ströher, U. Marburgvirus genomics and association with a large hemorrhagic fever outbreak in Angola. J. Virol. 2006, 80, $6497-6516$. [CrossRef]

10. Olival, K.J.; Hosseini, P.R.; Zambrana-Torrelio, C.; Ross, N.; Bogich, T.L.; Daszak, P. Host and viral traits predict zoonotic spillover from mammals. Nature 2017, 546, 646-650. [CrossRef] [PubMed]

11. Mollentze, N.; Streicker, D.G. Viral zoonotic risk is homogenous among taxonomic orders of mammalian and avian reservoir hosts. Proc. Natl. Acad. Sci. USA 2020, 117, 9423-9430. [CrossRef] [PubMed]

12. Leroy, E.M.; Kumulungui, B.; Pourrut, X.; Rouquet, P.; Hassanin, A.; Yaba, P.; Délicat, A.; Paweska, J.T.; Gonzalez, J.P.; Swanepoel, R. Fruit bats as reservoirs of Ebola virus. Nature 2005, 438, 575-576. [CrossRef]

13. Swanepoel, R.; Smit, S.B.; Rollin, P.E.; Formenty, P.; Leman, P.A.; Kemp, A.; Burt, F.J.; Grobbelaar, A.A.; Croft, J.; Bausch, D.G.; et al. Studies of reservoir hosts for Marburg virus. Emerg. Infect. Dis. 2007, 13, 1847-1851. [CrossRef]

14. Towner, J.S.; Amman, B.R.; Sealy, T.K.; Carroll, S.A.; Comer, J.A.; Kemp, A.; Swanepoel, R.; Paddock, C.D.; Balinandi, S.; Khristova, M.L. Isolation of genetically diverse Marburg viruses from Egyptian fruit bats. PLoS Pathog. 2009, 5, e1000536. [CrossRef]

15. Poon, L.L.M.; Chu, D.K.W.; Chan, K.H.; Wong, O.K.; Ellis, T.M.; Leung, Y.H.C.; Lau, S.K.P.; Woo, P.C.Y.; Suen, K.Y.; Yuen, K.Y.; et al. Identification of a novel coronavirus in bats. J. Virol. 2005, 79, 2001-2009. [CrossRef]

16. Li, W.; Shi, Z.; Yu, M.; Ren, W.; Smith, C.; Epstein, J.H.; Wang, H.; Crameri, G.; Hu, Z.; Zhang, H.; et al. Bats are natural reservoirs of SARS-like coronaviruses. Science 2005, 310, 676-679. [CrossRef] [PubMed]

17. Lau, S.K.P.; Woo, P.C.Y.; Li, K.S.M.; Huang, Y.; Tsoi, H.-W.; Wong, B.H.L.; Wong, S.S.Y.; Leung, S.-Y.; Chan, K.-H.; Yuen, K.-Y. Severe acute respiratory syndrome coronavirus-like virus in Chinese horseshoe bats. Proc. Natl. Acad. Sci. USA 2005, 102, 14040-14045. [CrossRef] [PubMed]

18. Memish, Z.A.; Mishra, N.; Olival, K.J.; Fagbo, S.F.; Kapoor, V.; Epstein, J.H.; Alhakeem, R.; Durosinloun, A.; Al Asmari, M.; Islam, A.; et al. Middle East respiratory syndrome coronavirus in bats, Saudi Arabia. Emerg. Infct. Dis. 2013, 19, 1819-1823. [CrossRef]

19. Markotter, W.; Geldenhuys, M.; Jansen van Vuren, P.; Kemp, A.; Mortlock, M.; Mudakikwa, A.; Nel, L.; Nziza, J.; Paweska, J.; Weyer, J. Paramyxo- and coronaviruses in Rwandan bats. Trop. Med. Infect. Dis. 2019, 4, 99. [CrossRef] [PubMed]

20. Geldenhuys, M.; Mortlock, M.; Epstein, J.H.; Pawęska, J.T.; Weyer, J.; Markotter, W. Overview of Bat and Wildlife Coronavirus Surveillance in Africa: A Framework for Global Investigations. Viruses 2021, 13, 936. [CrossRef]

21. Chua, K.B.; Bellini, W.J.; Rota, P.A.; Harcourt, B.H.; Tamin, A.; Lam, S.K.; Ksiazek, T.G.; Rollin, P.E.; Zaki, S.R.; Shieh, W.; et al. Nipah virus: A recently emergent deadly paramyxovirus. Science 2000, 288, 1432-1435. [CrossRef]

22. Halpin, K.; Young, P.L.; Field, H.E.; Mackenzie, J.S. Isolation of Hendra virus from pteropid bats: A natural reservoir of Hendra virus. J. Gen. Virol. 2000, 81, 1927-1932. [CrossRef]

23. Drexler, J.F.; Max Corman, V.; Müller, M.A.; Maganga, G.D.; Vallo, P.; Binger, T.; Gloza-Rausch, F.; Cottontail, V.M.; Rasche, A.; Yordanov, A.; et al. Bats host major mammalian paramyxoviruses. Nat. Commun. 2012, 3, 1-12. [CrossRef]

24. Mortlock, M.; Kuzmin, I.V.; Weyer, J.; Gilbert, A.T.; Agwanda, B.; Rupprecht, C.E.; Nel, L.H.; Kearney, T.; Malekani, J.M.; Markotter, W. Novel paramyxoviruses in bats from Sub-Saharan Africa, 2007-2012. Emerg. Infect. Dis. 2015, 21, 1840-1843. [CrossRef]

25. Van Thiel, P.P.; van den Hoek, J.A.; Eftimov, F.; Tepaske, R.; Zaaijer, H.J.; Spanjaard, L.; de Boer, H.E.; van Doornum, G.J.; Schutten, M.; Osterhaus, A.; et al. Fatal case of human rabies (Duvenhage virus) from a bat in Kenya: The Netherlands, December 2007. Eurosurveillance 2008, 13, 8007. [CrossRef]

26. Coertse, J.; Grobler, C.S.; Sabeta, C.T.; Seamark, R.C.J.; Kearney, T.; Paweska, J.T.; Markotter, W. Lyssaviruses in insectivorous bats, South Africa, 2003-2018. Emerg. Infect. Dis. 2020, 26, 3056-3060. [CrossRef]

27. Bausch, D.G.; Nichol, S.T.; Muyembe-Tamfum, J.J.; Borchert, M.; Rollin, P.E.; Sleurs, H.; Campbell, P.; Tshioko, F.K.; Roth, C.; Colebunders, R.; et al. Marburg hemorrhagic fever associated with multiple genetic lineages of virus. N. Engl. J. Med. 2006, 355, 909-919. [CrossRef]

28. Paweska, J.T.; Jansen van Vuren, P.; Masumu, J.; Leman, P.A.; Grobbelaar, A.A.; Birkhead, M.; Clift, S.; Swanepoel, R.; Kemp, A. Virological and serological findings in Rousettus aegyptiacus experimentally inoculated with Vero cells-adapted Hogan strain of Marburg virus. PLoS ONE 2012, 7, e45479. [CrossRef] [PubMed]

29. Paweska, J.T.; Jansen van Vuren, P.; Fenton, K.A.; Graves, K.; Grobbelaar, A.A.; Moolla, N.; Leman, P.; Weyer, J.; Storm, N.; McCulloch, S.D.; et al. Lack of Marburg virus transmission from experimentally infected to susceptible in-contact Egyptian fruit bats. J. Infect. Dis. 2015, 212, S109-S118. [CrossRef] [PubMed]

30. Amman, B.R.; Jones, M.E.B.; Sealy, T.K.; Uebelhoer, L.S.; Schuh, A.J.; Bird, B.H.; Clema-McCry, J.A.D.; Martin, B.E.; Nichol, S.T.; Towner, J.T. Oral shedding of Marburg virus in experimentally infected Egyptian fruit bats (Rousettus aegyptiacus). J. Wildl. Dis. 2015, 51, 113-124. [CrossRef]

31. Jones, M.E.; Schuh, A.J.; Amman, B.R.; Sealy, T.K.; Zaki, S.R.; Nichol, S.T.; Towner, J.S. Experimental inoculation of Egyptian Rousette bats (Rousettus aegyptiacus) with viruses of the Ebolavirus and Marburgvirus Genera. Viruses 2015, 7, 3420-3442. [CrossRef] [PubMed] 
32. Schuh, A.J.; Amman, B.R.; Jones, M.E.B.; Sealy, T.K.; Uebelhoer, L.S.; Spengler, J.R.; Martin, B.E.; Coleman-McCray, J.A.D.; Nichol, S.T.; Towner, J.S. Modelling filovirus maintenance in nature by experimental transmission of Marburg virus between Egyptian rousette bats. Nat. Commun. 2017, 8, 14446. [CrossRef]

33. Storm, N.; Jansen van Vuren, P.; Markotter, W.; Paweska, J.T. Virological and serological responses to experimental infection with Marburg virus in Egyptian rousette bats with pre-existing natural humoral immunity. Viruses 2018, 10, 73. [CrossRef]

34. Johnson, E.D.; Johnson, B.K.; Silverstein, D.; Tukei, P.; Geisbert, T.W.; Sanchez, A.N.; Jahrling, P.B. Characterization of a new Marburg virus isolated from a 1987 fatal case in Kenya. Arch. Virol. 1996, 11, S101-S114.

35. Centers for Disease Control and Prevention. Imported case of Marburg hemorrhagic fever-Colorado, 2008. Morb. Mortal. Wkly. Rep. 2009, 58, 1377-1381.

36. Adjemian, J.; Farnon, E.C.; Tschioko, F.; Wamala, J.F.; Byaruhanga, E.; Bwire, G.S.; Kansiimey, E.; Kagirita, A.; Ahimbisibwe, S.; Katunguka, F.; et al. Outbreak of Marburg hemorrhagic fever among miners in Kamwenge and Ibanda Districts, Uganda, 2007. J. Infect. Dis. 2011, 204, S796-S799. [CrossRef]

37. Timen, A.; Koopmans, M.P.G.; Vossen, A.C.T.M.; van Doornum, G.J.J.; Günther, S.; van den Berkmortel, F.; Verduin, K.M.; Dittrich, S.; Emmerich, P.; Albert, D.M.E.; et al. Response to imported case of Marburg hemorrhagic fever, The Netherlands. Emerg. Infect. Dis. 2009, 15, 1171-1175. [CrossRef]

38. Amman, B.R.; Carroll, S.A.; Reed, Z.D.; Sealy, T.K.; Balinandi, S.; Swanepoel, R.; Kemp, A.; Erickson, B.R.; Comer, J.A.; Campbell, S.; et al. Seasonal pulses of Marburg virus circulation in juvenile Rousettus aegyptiacus bats coincide with periods of increased risk of human infection. PLoS Pathog. 2012, 8, e1002877. [CrossRef]

39. Pawęska, J.T.; Storm, N.; Markotter, W.; Di Paola, N.; Wiley, M.R.; Palacios, G.; Jansen van Vuren, P. Shedding of marburgvirus in naturally infected Egyptian rousette bats, South Africa, 2017. Emerg. Infect. Dis. 2020, 26, 3051-3055. [CrossRef]

40. Martini, G. Marburg virus disease. Clinical syndrome. In Marburg Virus Disease; Martini, G., Siegert, R., Eds.; Springer: New York, NY, USA, 1971; pp. 1-9.

41. Edmond, R.T.D.; Evans, B.; Bowen, E.T.W.; Lloyd, G. A case of Ebola virus infection. Br. Med. J. 1977, 2, 541-544. [CrossRef]

42. Smith, D.H.; Johnson, B.K.; Isaacson, M.; Swanepoel, R.; Johnson, K.M.; Killy, M.; Bagshawe, A.; Siongok, T.; Keruga, W.K. Marburg-virus disease in Kenya. Lancet 1982, 1, 816-820. [CrossRef]

43. Rodriguez, L.L.; Roo, A.D.; Guimard, Y.; Trappier, S.G.; Sanchez, A.; Bressler, D.; Williams, A.J.; Rowe, A.K.; Bertolli, J.; Khan, A.S.; et al. Persistence and genetic stability of Ebola virus during the outbreak in Kikwit, Democratic Republic of the Congo, 1995. J. Infect. Dis. 1999, 179, S170-S176. [CrossRef] [PubMed]

44. Christie, A.; Davies-Wayne, G.J.; Cordier-Lasalle, T.; Blackley, D.J.; Laney, A.S.; Williams, D.E.; Shinde, S.A.; Badio, M.; Lo, T.; Mate, S.E.; et al. Possible sexual transmission of Ebola virus-Liberia, 2015. MMWR 2015, 64, 479-481. [PubMed]

45. Soka, M.J.; Choi, M.J.; Baller, A.; White, S.; Rogers, E.; Purpura, L.J.; Mahmoud, N.; Wasunna, C.; Massaquoi, M.; Abad, N.; et al. Prevention of sexual transmission of Ebola in Liberia through a national semen testing and counselling programme for survivors: An analysis of Ebola virus RNA results and behavioural data. Lancet Glob. Health 2016, 4, e736-e743. [CrossRef]

46. Uyeki, T.M.; Erickson, B.R.; Brown, S.; McElroy, A.K.; Cannon, D.; Gibbons, A.; Sealy, T.; Kainulainen, M.H.; Schuh, A.J.; Kraft, C.S.; et al. Ebola Virus Persistence in Semen of Male Survivors. Clin. Infect Dis. 2016, 62, 1552-1555. [CrossRef]

47. Subtil, F.; Delaunay, C.; Keita, A.K.; Sow, M.S.; Toure, A.; Leroy, S.; Msellati, P.; Magassouba, N.; Baize, S.; Raoul, H.; et al. Dynamics of Ebola RNA persistence in semen: A report from the postebogui Cohort in Guinea. Clin. Infect Dis. 2017, 64, 1788-1790. [CrossRef] [PubMed]

48. Sissoko, D.; Duraffour, S.; Kerber, R.; Kolie, J.S.; Beavogui, A.H.; Camara, A.-M.; Colin, G.; Rieger, T.; Oestereich, L.; Pályi, B.; et al. Persistence and clearance of Ebola virus RNA from seminal fluid of Ebola virus disease survivors: A longitudinal analysis and modelling study. Lancet Glob. Health 2017, 5, e80-e88. [CrossRef]

49. Diallo, B.; Sissoko, D.; Loman, N.J.; Bah, H.A.; Bah, H.; Worrell, M.C.; Conde, I.S.; Sacko, R.; Mesfin, S.; Loua, A.; et al. Resurgence of Ebola virus disease in Guinea linked to a survivor with virus persistence in seminal fluid for more than 500 days. Clin. Infect. Dis. 2016, 63, 1353-1366. [CrossRef]

50. Larsen, T.; Stevens, E.L.; Davis, K.J.; Geisbert, J.B.; Daddario-DiCaprio, K.M.; Jahrling, P.B.; Hensley, L.E.; Geisbert, T.W. Pathologic findings associated with delayed death in nonhuman primates experimentally infected with Zaire Ebola virus. J. Infect. Dis. 2007, 196, S323-S328. [CrossRef] [PubMed]

51. Howletty, P.; Brown, C.; Helderman, T.; Brooks, T.; LIsk, D.; Deem, G.; Solbrig, M.; Lada, M. Ebola virus disease complicated by late-onset encephalitis and polyarthritis, Sierra Leone. Emerg. Infect. Dis. 2016, 22, 150-152. [CrossRef]

52. Mattia, J.G.; Vandy, M.J.; Chang, J.C.; Platt, D.E.; Dierberg, K.; Bausch, D.G.; Brooks, T.; Conteh, S.; Crozier, I.; Fowler, R.A.; et al. Early clinical sequelae of Ebola virus disease in Sierra Leone: A cross-sectional study. Lancet Infect. Dis. 2016, 16, 331-338. [CrossRef]

53. Sissoko, D.; Laouenan, C.; Folkesson, E.; Lebing, A.B.; Beavogui, A.H.; Baize, S.; Camara, S.M.; Maes, P.; Shepherd, S.; Danel, C.; et al. Experimental treatment with favipiravir for Ebola virus disease (the JIKI Trial): A historically controlled, single-arm proof-of-concept trial in Guinea. PLoS Med. 2016, 13, e1001967. [CrossRef]

54. Schindell, B.G.; Webb, A.L.; Kindrachuk, J. Persistence and sexual transmission of filoviruses. Viruses 2018, 10, 683. [CrossRef]

55. Monath, T.P. Ecology of Marburg and Ebola: Speculation and directions for future research. J. Infect. Dis. 1999, 179, S127-S138. [CrossRef] 
56. Kuno, G.; Chang, G.J.J. Biological transmission of arboviruses; re-examination of and new insights into components, mechanism and unique traits as well as their evolutionary trends. Clin. Microbiol. Rev. 2005, 18, 608-637. [CrossRef] [PubMed]

57. Leitner, W.W.; Wali, T.; Kincaid, R.; Costero-Saint Denis, A. Arthropod Vectors and Disease Transmission: Translational Aspects. PLoS Negl. Trop. Dis. 2015, 9, e0004107. [CrossRef]

58. Martina, B.E.; Barzon, L.; Pijlman, G.P.; Joséde la Fuente, I.; Rizzoli, A.; Wammes, L.J.; Takken, W.; van Rij, R.P.; Papa, A. Human to human transmission of arthropod-borne pathogens. Curr. Opin. Virolol. 2017, 22, 13-21. [CrossRef] [PubMed]

59. Tortosa, P.; Dsouli, N.; Gomard, Y.; Ramasindrazana, B.; Dick, C.W.; Goodman, S.M. Evolutionary history of Indian Ocean Nycteribiid bat flies mirroring the ecology of their hosts. PLoS ONE 2013, 8, e75215. [CrossRef]

60. Bertola, P.B.; Aires, C.C.; Favorito, S.E.; Graciolli, G.; Amaku, M.; Pinto-da-Rocha, R. Bat flies (Diptera:Streblidae, Nycteribiidae) parasitic on bats (Mammalia: Chiroptera) at Parque da Cantareira, Sao Paulo, Brazil: Parasitism rates and host-parasite associations. Mem. Inst. Oswaldo Cruz. 2005, 100, 25-32. [CrossRef]

61. Dick, C.W.; Patterson, B.D. Bat flies: Obligate ectoparasites of bats. In Micromammals and Macroparasites; Morand, S., Krasnov, B.R., Poulin, R., Eds.; Springer: Tokyo, Japan, 2006; pp. 179-194.

62. Ramasindrazana, B.; Goodman, S.M.; Gomard, Y.; Dick, C.W.; Tortosa, P. Hidden diversity of Nycteribiidae (Diptera) bat flies from the Malagasy region and insights on host-parasite interactions. Parasit. Vectors 2017, 10, 630. [CrossRef]

63. Wilkinson, D.A.; Duron, O.; Cordonin, C.; Gomard, Y.; Ramasindrazana, B.; Mavingui, P.; Goodman, S.M.; Tortosa, P. The bacteriome of bat flies (Nycteribiidae) from the Malagasy region: A community shaped by host ecology, bacterial transmission mode, and host-vector specificity. Appl. Environ. Microbiol. 2016, 82, 1778-1788. [CrossRef] [PubMed]

64. Brook, C.E.; Bai, Y.; Dobson, A.P.; Osikowicz, L.M.; Ranaivoson, H.C.; Zhu, Q.; Kosoy, M.Y.; Dittmar, K. Bartonella spp. in fruit bats and blood-feeding ectoparasites in Madagascar. PLoS Negl. Trop. Dis. 2015, 10, e0003532. [CrossRef]

65. Morse, S.F.; Olival, K.J.; Kosoy, M.; Billeter, S.A.; Patterson, B.D.; Dick, C.W.; Dittmar, K. Global distribution and genetic diversity of Bartonella in bat flies (Hippoboscoidea, Streblidae, Nycteribiidae). Infect. Genet. Evol. 2012, 12, 1717-1723. [CrossRef] [PubMed]

66. Aznar-Lopez, C.; Vasquez-Moron, S.; Marston, D.A.; Juste, J.; Ibáñez, C.; Miguel Berciano, J.; Salsamendi, E.; Aihartza, J.; Banyard, A.; McElhinney, L.; et al. Detection of rhabdovirus viral RNA in oropharyngeal swabs and ectoparasites of Spanish bats. J. Gen. Virol. 2013, 94, 69-75. [CrossRef]

67. Goldberg, T.L.; Bennett, A.J.; Kityo, R.; Kuhn, J.H.; Chapman, C.A. Kanyawara virus: A novel rhabdovirus infecting newly discovered nycteribiid bat flies infesting previously unknown pteropodid bats in Uganda. Sci. Rep. 2017, 7, 5287. [CrossRef]

68. Obame-Nkoghe, J.; Rahola, N.; Bourgarel, M.; Yangari, P.; Prugnolle, F.; Maganga, G.D.; Leroy, E.M.; Fontenille, D.; Ayala, D.; Paupy, C. Bat flies (Diptera: Nycteribiidae and Streblidae) infesting cavedwelling bats in Gabon: Diversity, dynamics and potential role in Polychromophilus melanipherus transmission. Parasit. Vectors 2016, 9, 333. [CrossRef]

69. Kunz, C.; Hofmann, H. Some characteristics of the Marburg virus. In Marburg Virus Disease; Martini, G.A., Siegert, R., Eds.; Springer: Berlin, Germany, 1971; pp. 109-111.

70. Conrad, J.L.; Isaacsony, M.; Smith, E.B.; Wulff, H.; Crees, M.; Geldenhuys, P.; Johnston, J. Epidemiologic investigation of Marburg virus disease, Southern Africa, 1975. Am. J. Trop. Med. Hyg. 1978, 27, 1210-1215. [CrossRef] [PubMed]

71. Reiter, P.; Turell, M.; Coleman, R.; Miller, B.; Maupin, G.; Liz, J.; Kuehne, A.; Barth, J.; Geisbert, J.; Dohm, D.; et al. Field investigations of an outbreak of Ebola hemorrhagic fever, Kikwit, Democratic Republic of the Congo, 1995: Arthropod studies. J. Infect. Dis. 1999, 179 (Suppl. 1), S148-S154. [CrossRef]

72. Leirs, H.; Mills, J.N.; Krebs, J.W.; Childs, J.E.; Akaibe, D.; Woollen, N.; Ludwigg, G.; Peters, C.J.; Ksiazek, T.G. Search for the Ebola virus reservoir in the Democratic Republic of the Congo; refelections on vertebrate collection. J. Infect. Dis. 1999, 179 (Suppl. 1), S155-S163. [CrossRef]

73. Schuh, A.J.; Amman, B.R.; Apanaskevich, D.A.; Sealy, T.K.; Nichol, S.T.; Towner, J.S. No evidence for the involvement of the argasid tick Ornithodoros faini in the enzootic maintenance of marburgvirus within Egyptian rousette bats Rousettus aegyptiacus. Parasit. Vectors 2016, 9, 28. [CrossRef] [PubMed]

74. Paweska, J.T.; Jansen van Vuren, P.; Kamp, A.; Storm, N.; Grobbelaar, A.A.; Wiley, M.R.; Palacios, G.; Markotter, W. Marburg virus infection in Egyptian rousette bats, South Africa, 2013-2014. Emerg. Infect. Dis. 2018, 24, 1134-1137. [CrossRef] [PubMed]

75. Jansen van Vuren, P.; Wiley, M.; Palacios, G.; Storm, N.; McCulloch, S.; Markotter, W.; Birkhead, M.; Kemp, A.; Paweska, J.T. Isolation of a novel fusogenic orthoreovirus from Eucampsipoda africana bat flies in South Africa. Viruses 2016, 8, 65. [CrossRef]

76. Jansen van Vuren, P.; Wiley, M.R.; Palacios, G.; Storm, N.; Markotter, W.; Birkhead, M.; Kemp, A.; Paweska, J.T. Isolation of a novel orthobunyavirus from bat flies (Eucampsipoda africana). J. Gen. Virol. 2017, 98, 935-945. [CrossRef]

77. Jacobsen, N.H.G.; Du Plessis, E. Observations on the ecology and biology of the Cape fruit bat Rousettus aegyptiacus leachi in the Eastern Transvaal. S. Afr. J. Sci. 1976, 72, 270-273.

78. Theodor, O. The Nycteribiidae of the Ethiopian region and Madagascar. Parasitology 1957, 47, 457-543. [CrossRef]

79. Morrison, K. BaTML Factsheet: Harp Trapping; Guidance Notes for Bat Workers. BaTML Publications. 2005. Available online: www.batml.org.uk (accessed on 7 August 2021).

80. Theodor, O. On the genus Eucampsipoda Kol. and Dipseliopoda n.g. (Nycteribiidae, Diptera). Parasitology 1955, 45, 195-229. [CrossRef] [PubMed]

81. Zheng, H.; Li, A.Y.; Teel, P.D.; Pérez de León, A.A.; Seshu, J.; Liu, J. Biological and physiological characterization of in vitro blood feeding in nymph and adult stages of Ornithodoros turicata (Acari: Argasidae). J. Insect Physiol. 2015, 75, 73-79. [CrossRef] [PubMed] 
82. Chigusa, Y.; Ohshita, M.; Taya, J.; Kirinoki, M.; Yokoi, H.; Kawai, S.; Matsuda, H. Relationship between longevity and body weight in Glossina morsitans morsitans. Med. Entomol. Zool. 1997, 48, 91-96. [CrossRef]

83. Loder, P.M.J. Size of blood meals taken by tsetse flies (Glossina spp.) (Diptera: Glossinidae) correlates with fat reserves. Bul. Entomol. Res. 1997, 87, 547-549. [CrossRef]

84. Waite, J.L.; Henrt, A.R.; Adler, F.R.; Clayton, D.H. Sex-specific effects of an avian malaria parasite on an insect vector: Support for the resource limitation hypothesis. Ecology 2012, 93, 2448-2455. [CrossRef]

85. Theodor, O. A revision of the Streblidae (Diptera) of the Ethiopian Region. Trans. R. Entomol. Soc. Lond. 1968, 120, 313-373. [CrossRef]

86. Patterson, B.D.; Dick, C.W.; Dittmar, K. Roosting habits of bats affect their parasitism by bat flies (Diptera: Streblidae). J. Trop. Ecol. 2007, 23, 177-189. [CrossRef]

87. Huang, Y.-J.S.; Higgs, S.; Vanlandingham, D.L. Arbovirus-mosquito vector-host interactions and the impact on transmission and disease pathogenesis of arboviruses. Front. Microbiol. 2019, 10, 22. [CrossRef] [PubMed]

88. Mullens, B.A.; Gerry, A.C.; Lysyk, T.J.; Schmidtmann, E.T. Environmental effects on vector competence and virogenesis of bluetongue virus in Culicoides: Interpreting laboratory data in a field context. Vet. Ital. 2004, 40, 160-166.

89. Paweska, J.T.; Venter, G.J.; Mellor, P. Vector competence of South African Culicoides species for bluetongue virus serotype 1(BTV-1) with special reference to the effect of temperature on the rate of virus replication in C. imicola and C. bolitinos. Med. Vet. Entomol. 2002, 16, 10-21. [CrossRef] [PubMed]

90. Winokur, O.C.; Main, B.J.; Nicholson, J.; Barker, C.M. Impact of temperature on the extrinsic incubation period of Zika virus in Aedes aegypti. PLoS Negl. Trop. Dis. 2020, 14, e0008047. [CrossRef] [PubMed]

91. Merwaiss, F.; Filomatori, C.V.; Susuki, Y.; Bardossy, E.S.; Alvarez, D.E.; Saleh, M.-C. Chikungunya virus replication rate determines the capacity of crossing tissue barriers in mosquitoes. J. Virol. 2019, 5, e01956-20.

92. Franz, A.W.E.; Kantor, K.; Passarelli, A.L.; Clem, R.J. Tissue barriers to arbovirus infection in mosquitoes. Viruses 2015, 7, 3741-3767. [CrossRef]

93. Hardy, J.L.; Houk, E.J.; Kramer, L.D.; Reeves, W.C. Intrinsic factors affecting vector competence of mosquitoes for arboviruses. Annu. Rev. Entomol. 1983, 28, 229-262. [CrossRef]

94. Dick, C.W.; Dittmar, K. Parasitic Bat Flies (Diptera: Streblidae and Nycteribiidae): Host Specificity and Potential as Vectors. In Bats (Chiroptera) as Vectors of Diseases and Parasites, Parasitology Research Monographs 5; Klimpel, S., Mehlhorn, H., Eds.; Springer: Berlin/Heidelberg, Germany, 2014; pp. 131-155.

95. Ching, L.M.; Marshall, A.G. The breeding biology of the bat-fly Eucampsipoda sundaicum Theodor, 1955 (Diptera: Nycteribiidae). Malayan Nat. J. 1968, 21, 171-180.

96. Dittmar, K.; Porter, M.L.; Murray, S.; Whiting, M.F. Molecular phylogenetic analysis of nycteribiid and streblid bat flies (Diptera: Brachycera, Calyptratae): Implications for host associations and phylogeographic origins. Mol. Phylogenet. Evol. 2006, 38, 155-170. [CrossRef]

97. Marshall, A.G. The life cycle of Basilia hispida Theodor 1957 (Diptera: Nycteribiidae) in Malaysia. Parasitology 1970, $61,1-18$. [CrossRef]

98. Pilosof, S.; Dick, C.W.; Korine, C.; Patterson, B.D.; Krasnov, B. Effects of anthropogenic disturbance and climate on patterns of bat fly parasitism on bats. PLoS ONE 2012, 7, e41487. [CrossRef] [PubMed]

99. Lewis, S.E. Roost fidelity of bats: A review. J. Mammal. 1995, 76, 481-496. [CrossRef]

100. Reckardt, K.; Kerth, G. The reproductive success of the parasitic bat fly Basilia nana (Diptera: Nycteribiidae) is affected by the low roost fidelity of its host, the Bechstein's bat (Myotis bechsteinii). Parasitol. Res. 2006, 98, 237-243. [CrossRef] [PubMed]

101. Dittmar, K.; Dick, C.W.; Patterson, B.D.; Whiting, M.F.; Gruwell, M.E. Pupal deposition and ecology of bat flies (Diptera: Streblidae): Trichobius sp. (caecus group) in a Mexican cave habitat. J. Parasitol. 2009, 95, 308-314. [CrossRef] [PubMed]

102. Ramanantsalama, R.V.; Andrianarimisa, A.; Raselimanana, A.P.; Goodman, S.M. Rates of hematophagous ectoparasites consumption during grooming by an endemic Madagascar fruit bat. Parasit. Vectors 2018, 11, 330. [CrossRef] [PubMed] 